\title{
The Neogene Savannas of North America: A Retrospective Analysis on Artiodactyl Faunas
}

\author{
Nuria Melisa Morales-García ${ }^{*}$, Laura K. Säilä ${ }^{2}$ and Christine M. Janis ${ }^{1,3}$ \\ ${ }^{1}$ School of Earth Sciences, University of Bristol, Bristol, United Kingdom, ${ }^{2}$ Department of Geosciences and Geography, \\ University of Helsinki, Helsinki, Finland, ${ }^{3}$ Department of Ecology and Evolutionary Biology, Brown University, Providence, Rl, \\ United States
}

OPEN ACCESS

Edited by: Corwin Sullivan, University of Alberta, Canada

Reviewed by:

Terry A. Gates,

North Carolina State University,

United States

Subir Bera,

University of Calcutta, India

${ }^{*}$ Correspondence:

Nuria M. Morales-García

nm15309@my.bristol.ac.uk

Specialty section:

This article was submitted to

Paleontology,

a section of the journal

Frontiers in Earth Science

Received: 11 December 2019

Accepted: 13 May 2020

Published: 05 June 2020

Citation:

Morales-García NM, Säilä LK and Janis CM (2020) The Neogene

Savannas of North America:

A Retrospective Analysis on

Artiodactyl Faunas.

Front. Earth Sci. 8:191.

doi: 10.3389/feart.2020.00191
Savanna-like ecosystems were present at high latitudes in North America during much of the Neogene. Present-day African savannas, like the Serengeti, have been proposed to be modern analogs of these paleosavannas, particularly those from the middle Miocene of the Great Plains region of the United States. Both these extant and extinct savannas contain a preponderance of artiodactyl (even-toed ungulate) species; however, the taxonomic composition of each fauna is different. While present-day African savannas are dominated by ruminants (primarily bovids), the Neogene savannas of North America were dominated by a diversity of both camelid and non-bovid ruminant families. This study provides a quantitative test of the similarity of the artiodactyl faunas of the North American Neogene paleosavannas to those of the modern-day African savannas. A correspondence analysis of ecomorphological features revealed considerable overlap between modern and fossil faunas. The morphospace occupation of the extinct North American ruminants falls within that of the African bovids. Some of the extinct camelids also fall within this same morphospace, but many do not, perhaps indicating an environmental difference such as greater aridity in Neogene North America. The diversity and disparity of artiodactyl faunas through the Neogene of North America changed along with changing temperatures and precipitation regimes. The taxonomic and ecomorphological diversity of the Serengeti ruminant fauna is statistically comparable to those North American paleofaunas occurring during or immediately after the Middle Miocene Climatic Optimum (MMCO), but the later, more depauperate faunas are no longer comparable. This study quantitatively analyzes artiodactyl communities as they changed with the cooling and drying trend seen during the Neogene.

Keywords: ecomorphology, paleoecology, paleohabitat, Neogene, savanna ecosystems, camelids, ruminants

\section{INTRODUCTION}

Savanna ecosystems are a distinctive feature of today's world. The diversity of charismatic savanna animals, especially herds of large grazing ungulates such as wildebeest and zebra, makes such ecosystems well-known to scientists and the public alike. Savannas are largely tropical in distribution today, but in the Neogene similar ecosystems were apparent at higher latitudes, and savannas were absent from the tropics (Cerling, 1992; Kaya et al., 2018). How similar were such 
paleosavannas to those of today? Can a comparison of past and present ecosystems provide insights about how climatic and environmental changes have shaped the world and resulted in the familiar modern conditions?

Present-day savannas are highly seasonal, largely tropical grasslands with scattered drought-resistant trees and bushes, widespread in sub-Saharan Africa, but also present in South America, India and Australia (Shorrocks and Bates, 2015; Bache and Chesworth, 2016). African savannas, in particular, have a large taxonomic diversity of mammals, among which ungulates (hoofed mammals) are prominent (Shorrocks and Bates, 2015). In fact, African savannas have the highest diversity of ungulates on the planet (Du Toit and Cumming, 1999), and ungulates are much less diverse (or absent entirely) in savanna ecosystems on other continents. Ungulates comprise two related orders: Cetartiodactyla (even-toed ungulates), which includes ruminants (e.g., bovids, cervids, giraffids), suoids, camelids, hippopotamuses, and cetaceans; and Perissodactyla (odd-toed ungulates), which includes equids, tapirs and rhinoceroses. Elephants (order Proboscidea) and hyraxes (order Hyracoidea) are often considered "subungulates," and may be ungulate-like in their ecology, but are only distantly related to artiodactyls and perissodactyls. Here, we consider the African bovids (antelope and buffalo) and giraffe in comparison with the artiodactyls that made up the savanna faunas of the North American Neogene.

Extant terrestrial ungulates are mostly herbivorous, with diets varying from fruit, to browse (leaves of dicotyledonous plants), to grass, or some mixture thereof (most suoids, namely pigs and peccaries, are omnivorous). The diets of an ungulate assemblage reflect the nature of the vegetation available in the surrounding habitat. The diets of African savanna ungulates reflect their occurrence in grasslands with abundant trees and bushes: they range from pure browsing ( $>90 \%$ dicotyledonous leaves) to pure grazing (>90\% grass), with most species incorporating varying degrees of browse and grass in their diet depending on the season (Hoffman and Stewart, 1972; Shorrocks and Bates, 2015). The locomotor adaptations of ungulates also reflect their habitat, with an open habitat like a savanna containing a greater diversity of cursorial forms than a closed habitat like a forest. African ungulates mostly have limb morphologies indicative of cursorial locomotion, such as long slender legs (e.g., zebras, antelope) (Groves and Leslie, 2011; Rubenstein, 2011): but the morphology of some like the klipspringer (Oreotragus oreotragus), is more suited to jumping on rocky terrain (e.g., muscular and rounded hindquarters, standing on hoof tips; Estes, 2012).

Tropical savannas are a relatively recent (Plio-Pleistocene) phenomenon, and Africa has only housed this type of grassland habitat for the past 2-3 million years - areas that now contain savanna were formerly woodland or forest (Kaya et al., 2018; Fortelius et al., 2019). Grasslands at higher latitudes today are much less ecologically diverse, in terms of both fauna and flora, and contain few trees or shrubs and a limited diversity of ungulates: these grasslands are variously known as prairie (North America), pampas (South America), or steppe (Asia). However, temperatures were warmer at higher latitudes earlier in the Cenozoic (Zachos et al., 2001) and savanna ecosystems have been proposed as the habitat of ungulate-rich paleofaunas in the mid to late Miocene ( 15-8 Ma) of North America (e.g., Webb, 1977), South America (e.g., Webb, 1978), and Eurasia (e.g., Eronen et al., 2009): but even if a North American savanna were similar to one in Africa in terms of temperature and precipitation regimes, at a higher latitude the ecosystem would have been different in terms of annual changes in day length.

Here, we quantitatively compare the ungulate diversity of the best-known of the proposed Miocene savannas, that of the North American Great Plains region, to that of the bestknown African savanna, the Serengeti. Faunal differences in diversity of ecological characteristics (e.g., diet, locomotion) might reflect differences in the vegetation available within each fauna's habitat, but taxonomic differences reflect historical contingency, related to the earlier Cenozoic dispersal and radiation of mammals. The ungulates of the African savannas today are mostly artiodactyls from the family Bovidae, with a smaller diversity of giraffids, suids (pigs), hippopotamids, equids, rhinos and the ungulate-like proboscideans and hyracoids. The ungulates of the North American savannas were mostly equids and camelids, with a smaller diversity of non-bovid ruminants, tayassuids (peccaries), and other artiodactyls, such as oreodonts and protoceratids; rhinos, and other perissodactyls such as tapirs and chalicotheres; and proboscideans. Some of these forms had been present on the North American continent since the Eocene (e.g., equids and camelids), while others (e.g., horned ruminants and proboscideans) arrived via immigration events in the late early Miocene. Despite differences in taxonomic composition, past and present savanna ecosystems are considered to have been comparable in their diversity of ecomorphological types of mammals (e.g., grazing horses in North America versus grazing bovids in Africa, and giraffe-like camelids and hippo-like rhinos in North America).

We here present a quantitative investigation into the extent to which the North American Miocene savanna ecosystem resembled that of modern Africa in terms of the distribution of ecomorphologies in its ungulate fauna. If significant differences exist, what might that tell us about habitat and climatic differences between Neogene middle latitude areas and the present-day tropics?

\section{Faunal Correlates of Savanna Habitats}

Ideally, paleohabitats should be inferred based on fossil plants: but in many cases (and especially in older studies) accompanying paleobotanical information is not available for paleofaunal assemblages, and the types of animals present in the fauna have been used to make inferences about the faunal habitat. Quantitative studies have shown ungulates can certainly serve as reliable environmental proxies (e.g., Eronen et al., 2012). Savanna habitats have been inferred for faunas that, like modern savannas, contain a diversity of large ungulates comprising a mixture of browsers, grazers and mixed feeders, and also evidencing cursorial limb morphologies (see Webb, 1977). Morphological proxies are necessary to determine the probable diets and locomotor styles of extinct ungulates, especially if comparisons between fossil and recent ecosystems are to be made in a 
quantitative fashion. We discuss such proxies in more detail later when introducing the ones used in this study, but here we review a few of the issues.

The traditional indication of a grassland paleohabitat has been the relative height of the cheek teeth, or the "hypsodonty index," of the ungulates in the fauna; animals with a high index have been assumed to be grazers, thus evidencing the presence of grasses. Grazing ungulates today (e.g., equids, many bovids) are all highly hypsodont: high-crowned teeth are more resistant to a lifetime of wear, and phytoliths in grasses have been presumed to be the agents of dental abrasion. However, more recent studies have shown that the actual food eaten by hypsodont ungulates may not be the major agent of dental wear, but rather the dust on the food and accidentally ingested soil (see Damuth and Janis, 2011, for review). Hypsodonty is indicative of an abrasive diet consumed in an open habitat, which is possibly but not necessarily a diet of grass. The average hypsodonty index of modern ungulate faunas has been shown to correlate with annual precipitation, which in turn correlates with habitat openness (Eronen et al., 2012).

A number of morphological features have been shown to functionally correlate with diet and locomotion in extant ungulates, and these may be used as proxies to determine the behavior of extinct ungulates; however, such proxies may not be entirely "taxon free" (as per Damuth, 1982), as is often assumed, and phylogenetic influences may have a profound effect (see Barr, 2018, and Kovarovic et al., 2018, for recent reviews of ecomorphological proxies, phylogenetic issues, and the use of such proxies in habitat reconstruction). Phylogenetic issues relating to this study are considered in more detail below.

Several craniodental proxies have been proposed for determining diets of extinct ungulates (see Fraser and Theodor, 2011). Hypsodonty index (which can only be estimated on unworn teeth) is a primary proxy; other dental proxies include various aspects of tooth wear, such as mesowear (i.e., lifetime wear as evidenced by abrasion and attrition; Fortelius and Solounias, 2000), and microwear (i.e., quantification of microscopic scratches and pits produced by the last few meals of the animal; Solounias and Semprebon, 2002). Because dental wear is a phenotypic phenomenon it is usually assumed to be free of phylogenetic influence (but see Fraser et al., 2018). Hypsodonty index is somewhat influenced by phylogeny (e.g., equids are more hypsodont than bovids of similar grazing diet; Janis, 1988), but categories of hypsodonty (e.g., brachydont, mesodont, hypsodont; Fortelius et al., 2002) correlate fairly well with diet and habitat across extant ungulates (Damuth and Janis, 2011; Eronen et al., 2012).

Cranial dietary proxies include the shape of the muzzle (e.g., narrower muzzles are indicative of more selective feeding; Janis and Ehrhardt, 1988; Dompierre and Churcher, 1996), and those describing the size of the jaw adductor muscles, which are in turn related to the masticatory forces required to orally process browse or grass (e.g., animals with a more fibrous diet have a larger masseter muscle, and hence a larger angle of the dentary: Solounias et al., 1995; Clauss et al., 2008). Likewise, several proxies have been proposed for determining the locomotor type of extinct ungulates. Ungulates in more open habitats have a more "cursorial" type of limb morphology, including relatively longer distal limb segments, and their limbs are more restricted in motion to the parasagittal plane. Specific postcranial proxies include ones related to the morphology of the femur (e.g., Kappelman, 1988; Kappelman et al., 1997; Janis et al., 2012), metapodials (e.g., Scott and Barr, 2014) and phalanges (e.g., Luoys et al., 2013).

\section{Issues of Phylogeny}

Ungulate ecomorphological proxies have primarily been determined in African bovids: this assemblage offers a diversity of body sizes, diets and locomotor types, and these modern faunas have been of especial interest for inferring relatively recent (Plio-Pleistocene) African paleohabitats in connection with studies of human evolution (e.g., Kappelman et al., 1997; Plummer et al., 2015; Lehmann et al., 2016). But a problem in considering other ungulate families (e.g., equids) is that there is no comparable diversity of extant forms that can be used to establish ecomorphological proxies. In general, other ruminants can be compared with bovids (although bovids tend to be more hypsodont than cervids of similar diet; see Janis, 1988), but bovid-based proxies cannot be used to quantitatively determine the ecomorphology of suoid artiodactyls; suoids differ greatly from ruminants in their craniodental anatomy, and they have relatively shorter limbs. Such phylogenetic issues also arise when considering the other non-ruminant large herbivorous mammals of the North American Miocene savannas. Proboscideans and rhinos are very different to bovids in their craniodental and skeletal anatomy, as well as being much larger, and their ecomorphology obviously cannot be determined from bovidbased proxies. However, both camelids and equids are somewhat similar to bovids in overall size and general appearance, and we contrast these taxa below.

Equids were the most common and diverse ungulates in the North American savannas, comparable in their diversity of sizes and diets to African antelope today (see Webb, 1977). We attempted to include equids in this study but discovered that, while the hypsodont ones (subfamily Equinae) more or less clustered with the grazing bovids (as did the zebra, Equus burchelli, in the Serengeti fauna), the brachydont ones (subfamily Anchitheriinae, a little-appreciated yet important element of the North American savanna faunas until the latest Miocene) clustered in their own portion of the morphospace (Appendix 1), far removed from the browsing bovids that they resemble in hypsodonty and dental wear (see Semprebon et al., 2019). Although equids superficially resemble ruminants in their long faces and relatively elongated distal limb proportions, they differ in some critical ways. Equids, for example, being hindgut fermenters, have relatively larger masseter muscles than ruminants of similar diets, and so have a differently shaped mandible. This is not only apparent in extant animals, but the brachydont (presumed browsing) anchitheriine equids also have a relatively deep mandibular angle, very unlike browsing bovids. Regrettably, we found no way to adjust the parameters of our morphological proxies in such a way that the anchitheriine equids could be compared with bovids that they resembled ecologically and so we decided to limit our study to the artiodactyls. 
The camelids proved to be more comparable to ruminants. Camelids have commonly been considered as the sister taxon to the ruminants based on craniodental characters (the grouping of the two forming the "Neoselenodonta" of Webb and Taylor, 1980), although many molecular studies show camelids to be less closely related to the ruminants than are suoids (e.g., Price et al., 2005; but see Zurano et al., 2019, which places camelids as the sister taxon to ruminants plus cetaceans). However, camelids resemble ruminants in having selenodont molars, relatively long limbs (albeit with a different, secondarily digitigrade, foot posture), and a generally similar cranial shape, although they are certainly not morphologically identical (e.g., camelids have a relatively shorter premolar row, and tend to have proportionally longer distal limb segments). The North American camelids mostly cluster in a different portion of the morphospace to the African ruminants, and such morphological differences might be considered to represent phylogeny rather than ecomorphology. However, extant camelids overlap with ruminants in the morphospace (see Figure 6B). We discuss extensively in the text why we consider that, although phylogeny may play a role, the position of camelids in our morphospace may indeed carry a genuine ecomorphological signal, indicative of habitat and ecosystem differences between the North American Neogene and present-day Africa.

\section{History of Ideas About Paleosavannas}

Traditionally, the presence of paleosavannas in fossil ecosystems was determined using mammalian assemblages because little paleobotanical evidence was available. Webb (1977) suggested that the occurrence of large mammals with hypsodont cheek teeth and cursorial limb morphologies indicated the presence of savannas, as demonstrated especially in the middle Miocene of North America by the diversification of horses in the subfamily Equinae.

While macrofossils of plants are rare in paleofaunal assemblages, microfossils in the form of phytoliths may be plentiful; the research of Strömberg $(2002,2004,2011)$ in the past couple of decades shows that phytoliths can provide direct evidence about the floral assemblage, and hence the habitat. For example, Strömberg et al. (2013) found evidence of hypsodonty predating the presence of open environments in South America, whereas hypsodonty postdated the origin of grasslands in North America (Strömberg, 2002). Strömberg et al. (2013) concluded that there is no simple correlation between hypsodonty and grassy and/or open habitats: rather, abrasive diets are the important factor, and such diets may be independent of open habitat environments. Therefore, one should be cautious when trying to reconstruct paleoenvironments using the hypsodonty of mammalian assemblages as the sole line of evidence. Paleobotanical evidence, like phytolith assemblages (e.g., Strömberg, 2002, 2004, 2011; Strömberg et al., 2013), and paleosols (e.g., Fox and Koch, 2004) should also be considered whenever possible.

Figure 1 highlights the different perspectives regarding the evolution of ecosystems in North America during the Cenozoic. The older hypothesis (Webb, 1977) proposed that changes in the morphology of ungulates throughout the Cenozoic are indicative of changing ecosystems. Based on the presence of relatively large vertebrates in the Rocky Mountain Region during the late Paleocene (e.g., sheep to pig-sized phenacodontid condylarths and tapir-sized ungulate-like mammals such as pantodonts), Webb (1977) postulated the existence of "protosavannas" - small patches of open country amid predominant sub-tropical forests covering most of the continent. Webb (1977) also suggested that more open habitats first appeared in North America as early as the middle Eocene, based on botanical and sedimentological evidence from the Rocky Mountain Region that points to an increase in seasonal aridity, as well as what were then the oldest known grasses. Further evidence stemming from mammalian assemblages includes the decline of arboreal species (especially primates) and the development of "special adaptations" in some taxa to open-habitat living (e.g., development of more lophodont dentitions and more elongated limbs). Additionally, he highlighted the immigration of relatively open-habitat lineages from the Old World into North America during the late Eocene, including camels, hornless ruminants, and rabbits.

Webb (1977) proposed that open woodlands were expanding by the Oligocene, as evidenced by the diversification of mammalian taxa, the presence of mesodont and hypsodont teeth in some species (e.g., the diminutive hypertragulid Hypisodus), and the existence of highly specialized fossorial insectivorans (Eulipotyphla) such as Proterix and Cryptoryctes. By the middle Miocene, the high diversity of ungulates in North America was indicative of a savanna ecosystem fully comparable to that of the present-day African savannas: the fauna included rhinos, proboscideans, and hypsodont ruminants and equids, and many Miocene ungulate taxa had open-habitat adaptations, both dental (i.e., hypsodonty) and locomotor (e.g., long distal limb segments). Nonetheless, a considerable diversity of brachydont, shorterlegged ungulates persisted well into the late Miocene, which Webb (1977) attributed to the presence of riparian forests interdigitating with the predominant woodland savanna. By the Pliocene, the replacement of woodland savanna by steppe in the Great Plains was evidenced by the near absence of browsing species, the decrease in diversity of hypsodont species, and the concomitant decrease in the overall diversity of ungulates (Webb, 1977).

A more recent hypothesis, proposed by Strömberg (2011), is based on paleobotanical evidence, including macrofossils and phytoliths, as well as paleosols (Figure 1) [see also earlier discussion of North American grassland evolution by Jacobs et al. (1999) and Retallack (1997)]. Macrofossil evidence and palynofloras suggest the presence of subtropical-tropical evergreen or semideciduous forests across North America for most of the Eocene, although the oldest grass macrofossils on this continent date back to the earliest Eocene (55 Ma) (Strömberg, 2011). Woodland savanna-like ecosystems developed in the middle Eocene and persisted into the early Miocene; however, these ecosystems were not dominated by grasses, but rather by small trees and shrubs (Strömberg, 2011). Macrofossil evidence suggests that it was not until the middle to late Miocene that grasses spread across North America (Strömberg, 2011). Phytolith assemblages tell a different story, with grasses being present in forests by the earliest Oligocene and woodland 


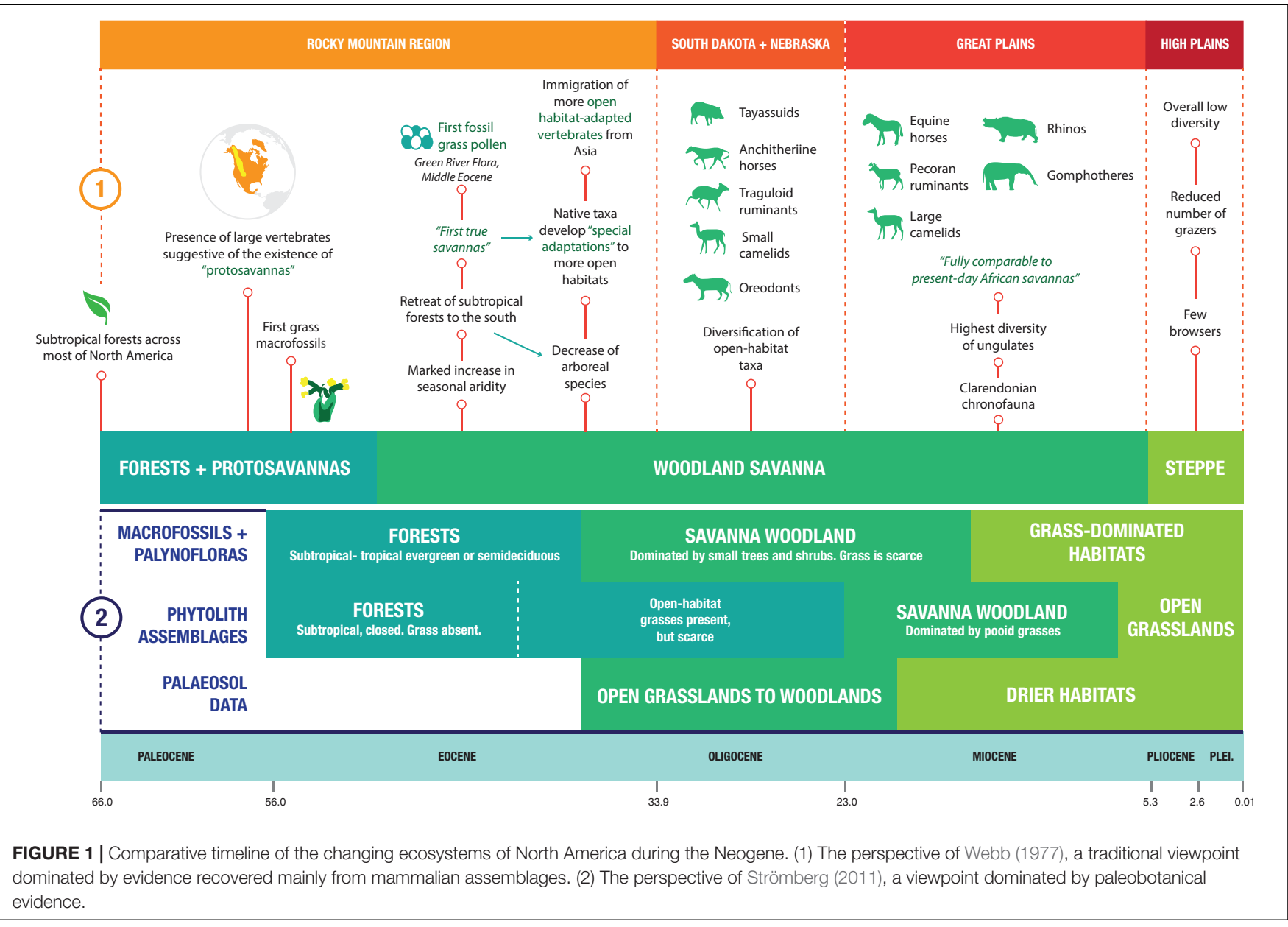

savannas dominated by pooid grasses by the late Oligoceneearly Miocene (Strömberg, 2011), preceding the radiation of hypsodont horses by around five million years. Phytolith evidence indicates that open grasslands first appeared in North America by the latest Miocene (Strömberg, 2011). Paleosol data indicate the presence of open grassland to woodland environments between the late Eocene and the early Miocene, and the development of drier habitats by the early Miocene (Strömberg, 2011); however, paleosols indicative of more open (i.e., more arid) grasslands are not apparent in the North American Great Plains area until the latest Miocene (around $6 \mathrm{Ma}$ ) (Retallack, 1997). In addition, changes in Neogene soil oxygen isotopes reflect the shift in the hydrological cycle that was effected by the transition to grasslands from environments with abundant tree cover: the late Neogene expansion of grasslands had a feedback effect in increasing environmental patterns of seasonality and aridity, and grassland expansion in general has been a powerful driver of global environmental change (Mix et al., 2013; Chamberlain et al., 2014).

There has been much discussion over the past few decades about the point in time in which Neogene grasslands transitioned from $\mathrm{C}_{3}$ photosynthesis to $\mathrm{C}_{4}$ photosynthesis (generally held to have happened in the latest Miocene, around 6-8 Mya), and the role of declining atmospheric $\mathrm{CO}_{2}$ in forcing this change (see Fox et al., 2018, for review). However, it is not clear how much this transition affected the grazing ungulates: certainly, as noted above, there is abundant evidence for $\mathrm{C}_{3}$ grasslands, and grazers feeding on them, in the middle to early late Miocene, and a transition in mode of plant synthesis may not have had a significant effect on herbivore foraging.

Of special interest here are the woodland savannas and grass-dominated habitats present in North America during the Neogene (Miocene and Pliocene) and, in particular, the notion that the ungulate assemblages from the Miocene savannas of North America were fully analogous in their ecomorphology to those of the present-day African savannas as proposed by Webb (1977, 1983b). In terms of the taxonomic composition of the large herbivorous mammal fauna, modern African savannas are dominated by bovid ruminants; other artiodactyl taxa such as giraffes, suids (pigs) and hippopotamuses are also present, along with perissodactyls like equids (zebras) and rhinos, and proboscideans (elephants) (Shorrocks and Bates, 2015). The Neogene savannas of North America were also dominated by artiodactyls, and both perissodactyls (equids and rhinos) and proboscideans (gomphotheres and mastodons) were also present. However, the artiodactyl taxonomic composition differed from that seen in present-day Africa and included tayassuids (peccaries), camelids (and the extinct, possibly 
camel-related, oreodonts and protoceratids), and non-bovid ruminants such as dromomerycids, antilocaprids (pronghorns), and a diversity of small hornless taxa (Janis et al., 2004); see later detailed description of the taxa present. The extant diversity of North American cervids and bovids arose from two separate immigration events from Eurasia, during the Pliocene and Pleistocene (Webb, 1998a). Unlike the fauna of modern African savannas, which contains a single genus of equids (and rarely more than one sympatric species in any faunal assemblage), equids were prominent members of the Neogene North American ecosystems, with over 20 genera present in the Miocene and Pliocene, and up to eight sympatric species in paleoassemblages (MacFadden, 1998).

Despite the differences in taxonomic composition, many of the extinct ungulates from the North American savanna paleofaunas have been proposed as ecomorphological analogs of modern-day African ungulates: e.g., the "giraffe-like camel" Aepycamelus, the "gazelle-like camel" Stenomylus, and the "hippo-like" teleoceratinae rhinos (Webb, 1983b). While both extant and extinct faunas appear to contain a similar diversity of ungulate species and feeding categories, this notion of savanna faunal similarity has never been examined quantitatively. In this paper, we analyze the morphospace occupation of artiodactyls in the present-day Serengeti National Park and selected Neogene faunal assemblages from the North American Great Plains, using ecomorphological traits indicative of ungulate feeding and habitat preference. Additionally, we analyze changes in morphospace occupation through time in the selected North American artiodactyl faunas, in the context of changing prevailing environmental conditions. This study represents the first quantitative characterization of the Neogene savannas of North America in terms of the ecomorphological traits of ungulates, and investigates the similarities and differences in artiodactyl ecomorphological diversity between the savannas of present-day Africa and the Neogene of North America.

\section{MATERIALS}

The artiodactyl taxa from the present-day Serengeti National Park, Tanzania, included in this analysis comprise 22 species of bovid and one species of giraffid (Appendix 2). The extinct North American taxa were the ones contained in eleven faunas from the Central Great Plains (Nebraska, Kansas and South Dakota; Figure 2) considered by Janis et al. (2004). These faunas were obtained from single localities (usually well-defined quarries) that contained the maximum alpha diversity present for each subdivision of the various North American Land Mammal Ages (NALMAs) throughout the Miocene (with the exception of the earliest subdivisions of the Arikareean, Ar1-Ar3), Pliocene and early Pleistocene (19.5$1.9 \mathrm{Ma})$. Forty-two taxa belonging to the extant artiodactyl families Camelidae (16 taxa), Antilocapridae (8), and Moschidae (5), and the extinct families Dromomerycidae (9), Gelocidae (1), Hypertragulidae (1), Leptomerycidae (1) and Protoceratidae (1), were represented at these localities. Dromomerycids were medium-sized cervid-related ruminants; gelocids were small basal ruminants; hypertragulids and leptomerycids were small (i.e., size of a duiker) traguloids; and protoceratids were related to either ruminants or camelids, the Miocene taxa being mediumsized (i.e., around the size of a large deer) with paired frontal horns and a sling-shot-like nasal horn. Following Janis et al. (2004) tayassuids (peccaries) were not included in the analysis due to their low alpha diversity and predominantly omnivorous diets. Oreodonts (rare in the Miocene faunas after the earliest part of the epoch) were also excluded given their morphological differences from camelids and ruminants (relatively short legs and short snouts). Appendix 3 presents a full list of the localities, together with their ages and the taxa they contained.

Morphological information on the skulls, mandibles and metatarsals of the extant taxa were obtained from photographs taken from the Field Museum (FMNH), the Smithsonian National Museum of Natural History (USNM) and the University of Michigan Museum of Zoology (UMMZ) via the Animal Diversity Web $\left(\mathrm{ADW}^{1}\right)$. Morphological information on the skulls, mandibles and metatarsals of the extinct taxa was obtained from the following sources: photographs taken at the American Museum of Natural History (AMNH) by CJ; photographs from online databases of the AMNH, the University of California Museum of Paleontology (UCMP), the University of Florida Museum of Natural History (UF), the Smithsonian National Museum of Natural History (USNM), the Yale Peabody Museum of Natural History (YPM), and the Museum für Naturkunde in Berlin (MfN); and the literature (Wortman, 1898; Matthew, 1908; Frick, 1937; Hibbard, 1951; Patton and Taylor, 1971; Taylor and Webb, 1976; Harrison, 1979; Webb, 1983a; Kelly, 1992; Morgan and White, 2005; Webb and Meachen, 2004; Prothero, 2008; Prothero and Liter, 2008; Prothero et al., 2008; Jimenez-Hidalgo and Carranza-Castañeda, 2010).

\section{METHODS}

Eleven measurements of each taxon were taken in ImageJ (Schneider et al., 2012) as shown in Figure 3. The cranial measurements were size-normalized by dividing by the molar row length [shown to have the best correlation with body mass of any craniodental measurement in extant ungulates by Janis (1990)]. Metatarsal slenderness was estimated by dividing the articular length by the midshaft mediolateral width. These measurements were then used to establish discrete categories for each morphological variable, so that all variables used in the analyses were categorical rather than absolute (see Werdelin and Lewis, 2013; Croft et al., 2017). We used discrete characters following Werdelin and Lewis (2013) and, because not all traits could be evaluated directly in all taxa, some data were obtained from congeners (as in Werdelin and Lewis, 2013). Correspondence analysis was specifically designed for discrete characters and has an established history in paleoecology (see Greenacre and Vrba, 1984). Variables were discretized based on qualitative assessments of the taxa (considering the different morphologies of extant taxa of known diets), to

\footnotetext{
${ }^{1}$ https://animaldiversity.org
} 


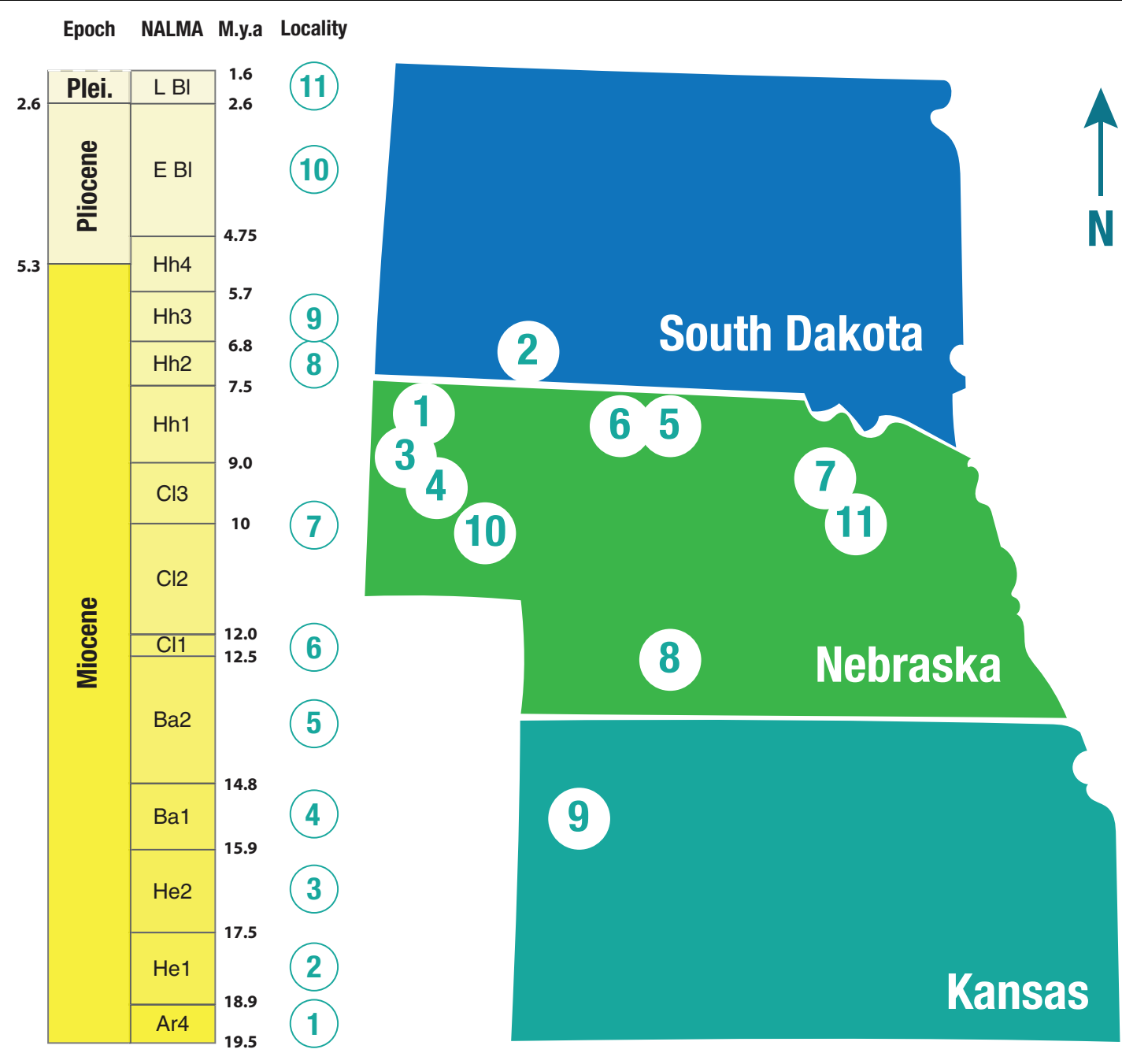

\section{0 km}

FIGURE 2 | Geographic distribution of the ungulate faunas used in this study: 1-Morava Ranch Quarry, Marsland Formation (13 ungulate taxa); 2-Flint Hill Local Fauna, Batesland Formation (16 ungulate taxa); 3-Thomson Quarry, Sheep Creek Formation (26 ungulate taxa); 4-Echo Quarry, Olcott Formation (25 ungulate taxa); 5-Norden Bridge Quarry Local Fauna, Valentine Formation (29 ungulate taxa); 6-Burge Quarry Fauna, Valentine Formation (21 ungulate taxa); 7-Blue Jay Quarry, Ash Hollow Formation (14 ungulate taxa); 8-Cambridge Local Fauna (Ft-40), Ash Hollow Formation (16 ungulate taxa); 9-Edson Quarry Fauna, Ogallala Formation (13 ungulate taxa); 10-Broadwater Local Fauna, Broadwater Formation (6 ungulate taxa); 11-Big Springs Local Fauna, Long Pine Formation (9 ungulate taxa). NALMA, North American Land Mammal Age; M.y.a., million years ago; Plei., Pleistocene; Ar, Arikareean; He, Hemingfordian; Ba, Barstovian; Cl, Clarendonian; Hh, Hemphillian; E BI, Early Blancan; L BI, Late Blancan. For a full breakdown of the ungulate taxa in each fauna, please refer to Supplementary Information.

construct bins of relatively equal distribution. Hypsodonty was calculated by dividing the crown height of the tallest unworn lower molar by its width [data taken from Janis (1988), and unpublished data]. Appendix 4 lists the categorical variables and their criteria. Muzzle width, which has been used as a proxy to distinguish between browsing and grazing ungulates (e.g., Janis and Ehrhardt, 1988; Pérez-Barbería and Gordon, 2001), could not be calculated here due to the lack of ventral view images of the skulls of many taxa. For the extant mammals, body mass data were obtained from the literature
(Wilson and Mittermeier, 2011); for the fossil mammals, body mass estimates were obtained from the NOW database (Fortelius, 2016) and the Supplementary Information of Tomiya (2013) and Saarinen et al. (2014). The body mass data were used to assign taxa to body size classes (see Appendix 4 for a detailed explanation). Eight ecomorphological traits [i.e., morphological features that reflect ecological characteristics of an animal, such as dietary preference or habitat choice (Wesley-Hunt et al., 2010): Table 1], were evaluated using the categorical variables outlined in Table 1, which also highlights their ecological significance. 


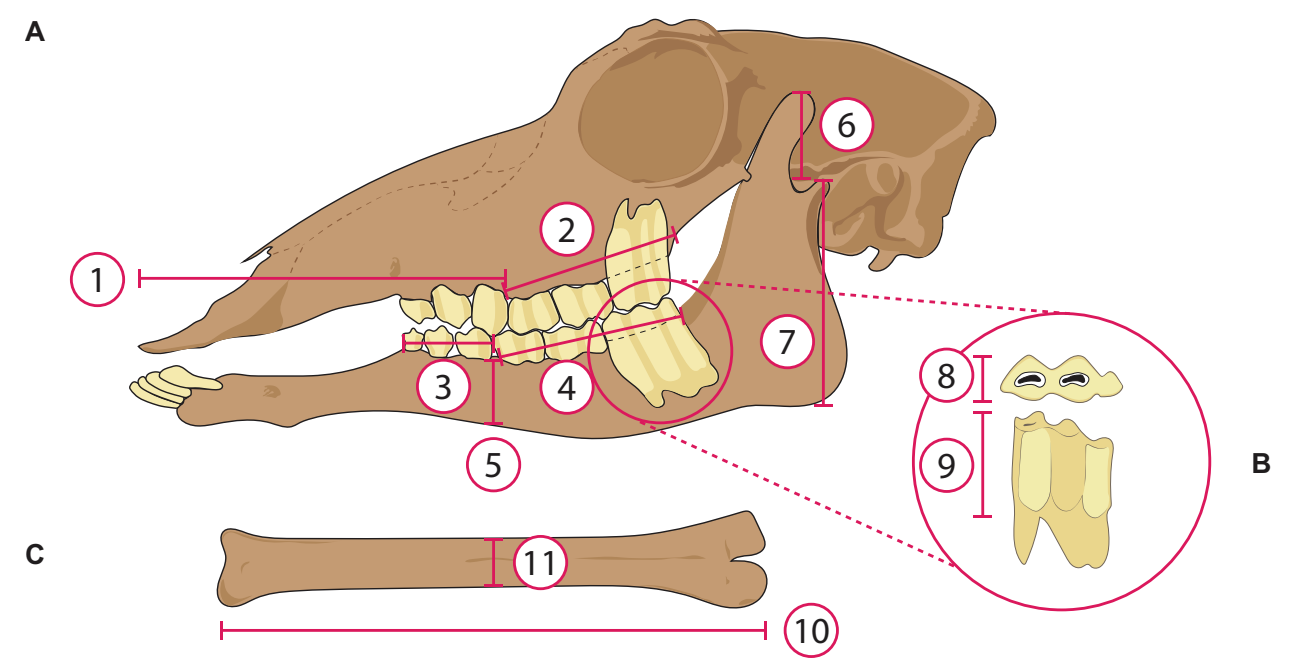

FIGURE 3 | Measurements taken from osteological material of extant and extinct artiodactyls. (A) Lateral view of the skull, (1) length of anterior portion of skull; (2) length of upper molar row (measured along the alveolar row); (3) length of lower premolar row (measured along the alveolar row); (4) length of lower molar row; (5) depth of the jaw corpus, taken at the boundary of the molar and premolar row; (6) moment arm of temporalis; (7) moment arm of masseter. (B) Occlusal (above) and labial (below) view of a lower third molar, (8) occlusal width of the m3, (9) crown height of the m3. (C) Metatarsal, (10) length of the metatarsal, (11) width of the metatarsal. Not to scale. Skull of the antilocaprid Plioceros modified from Frick (1937).

TABLE 1 | Categorical variables used in the correspondence analysis and their ecological significance.

\begin{tabular}{|c|c|c|}
\hline Variable & Functional significance & References \\
\hline Hypsodonty & $\begin{array}{l}\text { Reflects lifetime wear of teeth. Hypsodont (high-crowned) cheek teeth are indicative of } \\
\text { abrasive diets, including both grasses and ingested soil and environmental grit in open } \\
\text { habitats. Browsers = brachydont (low-crowned); mixed-feeders = mesodont to } \\
\text { hypsodont; grazers = hypsodont. }\end{array}$ & $\begin{array}{l}\text { Janis and Fortelius (1988); Damuth and } \\
\text { Janis (2011); Fraser and Theodor } \\
\text { (2011) }\end{array}$ \\
\hline $\begin{array}{l}\text { Relative length of } \\
\text { anterior face }\end{array}$ & $\begin{array}{l}\text { Correlates with feeding level and/or selectivity. Grazers feed at ground level; a long face } \\
\text { results in more elevated eyes, providing both protection from the grass and the ability to } \\
\text { spot predators while feeding. Browsers = short (with the exception of long-jawed high } \\
\text { level browsers); mixed feeders = variable; grazers = long. }\end{array}$ & $\begin{array}{l}\text { Janis (1995); Clauss et al. (2008); } \\
\text { Mendoza and Palmqvist (2008) }\end{array}$ \\
\hline $\begin{array}{l}\text { Relative depth of } \\
\text { jaw corpus }\end{array}$ & $\begin{array}{l}\text { Reflects space within the jaw beneath the tooth row needed to accommodate roots of } \\
\text { the cheek teeth. A more robust jaw may additionally reflect greater torsional forces. } \\
\text { Browsers = shallow jaw; mixed-feeders = intermediate to deep jaw; grazers = deep jaw. }\end{array}$ & Janis, 1995 \\
\hline $\begin{array}{l}\text { Relative length of } \\
\text { masseter moment } \\
\text { arm }\end{array}$ & $\begin{array}{l}\text { The depth of the angle of the dentary reflects the moment arm of the masseter, and } \\
\text { deeper jaws also reflect a relatively larger masseter muscle. The masseter muscle } \\
\text { produces the lateral movement of the jaw: a larger masseter is associated with more } \\
\text { abrasive diets and likely reflects a greater degree of oral food processing. } \\
\text { Browsers = short; mixed feeders = intermediate to long; grazers = long. }\end{array}$ & $\begin{array}{l}\text { Fraser and Theodor (2011); Varela and } \\
\text { Fariña (2015) }\end{array}$ \\
\hline $\begin{array}{l}\text { Relative metatarsal } \\
\text { length }\end{array}$ & $\begin{array}{l}\text { Correlates with habitat preference and cursoriality. Open-habitat dwellers specialized for } \\
\text { speed = long metapodials; closed or partly open habitats = intermediate metapodial } \\
\text { length; mountain dwellers specialized for climbing = short metapodials. }\end{array}$ & Scott (1985) \\
\hline Body size category & $\begin{array}{l}\text { Correlates with feeding style and food-selection ability. Larger body sizes are correlated } \\
\text { with ability to tolerate lower quality diets. }\end{array}$ & Peters, 1983 \\
\hline
\end{tabular}

Ecomorphological information obtained from: (1) Peters (1983), (2) Scott (1985), (3) Janis and Fortelius (1988), (4) Janis (1990), (5) Greaves (1991), (6) Janis (1995), (7) Pérez-Barbería and Gordon (1999), (8) Mendoza et al. (2002), (9) Clauss et al. (2008), (10) Mendoza and Palmqvist (2008), (11) Damuth and Janis (2011), (12) Fraser and Theodor (2011), (13) Varela and Fariña (2015). 
The data matrix of 76 taxa and eight categorical variables is presented in Appendix 5.

The comparative morphospace occupation of the extinct and extant artiodactyls considered here was visualized by means of a correspondence analysis of discrete characters performed in PAST 3.11 (Hammer et al., 2001) following the methodology of Werdelin and Lewis (2013), who used this method to study craniodental characters of extant and Plio-Pleistocene African carnivorans and to track the functional richness of communities through time (see also Croft et al., 2017, for the use of this methodology). Here, we implemented part of their methodology in artiodactyl communities of North America throughout the Neogene, with the aim of analyzing changes in diversity and disparity through time and potentially discriminating between camelids and ruminants in ecological terms. The first two axes of the resulting correspondence analysis were plotted in Numbers 3.6.2 to visualize the distribution of the taxa within the morphospace and their degree of morphological and ecological differentiation. The functional diversity of the communities was depicted by fitting convex hulls around the data (Werdelin and Lewis, 2013). The incorporation of the extant African taxa into the study (which belong to the same order, but to different families, as the Neogene taxa of North America) served to confirm that the results of the analysis reflected a true ecological signal, rather than a phylogenetic one.

We also performed phylogenetic flexible discriminant analysis (phylo FDA) following Motani and Schmitz (2011). This analysis was performed to determine the posterior probability that each of the extinct taxa belonged to any of our three dietary categories (i.e., browsers, grazers, or mixed feeders) considering the phylogenetic relationships of the taxa involved. Extant camelids were incorporated into this analysis. This analysis was performed in RStudio 1.2.1335 (RStudio Team, 2015) using the packages ape 5.3 (Paradis and Schliep, 2018), class 7.3-15 (Venables and Ripley, 2002), geiger 2.0.6.2 (Pennell et al., 2014), lattice 0.20-38 (Sarkar, 2008), mda 0.4-10 (Hastie et al., 1994), nnet 7.3-12 (Venables and Ripley, 2002), using the source data (phylo.fda.v0.2.R) of Motani and Schmitz (2011).

A time-scaled phylogeny (see Appendix 6) was used to perform the phylogenetic FDA. The phylogeny used in this study was built in Mesquite version 3.6 following previously published phylogenies by Honey et al. (1998), Janis and Manning (1998a; 1998b), Webb (1998b), Janis et al. (2002a; 2002b), Geisler and Uhen (2005); Davis (2007), Scherer (2013), and Zurano et al. (2019). Information on the first and last appearance dates of the taxa, as well as divergence dates, were obtained from the references above plus Prothero (1998); Webb and Meachen (2004), and Baskin and Thomas (2015). The phylogeny was time scaled in RStudio 1.2.1335 (RStudio Team, 2015) using the 'equal' method of Brussatte et al. (2008) with the package 'paleotree' 3.3.0 (Bapst, 2012).

One-way permutational multivariate analyses of variance (i.e., PERMANOVAs) were performed to test for differences between taxonomic groups, dietary groups and faunas using all row scores from the correspondence analysis in PAST 3.11 (Hammer et al., 2001). Euclidean similarity and distance indices were calculated in PAST 3.11 (Hammer et al., 2001) using the correspondence analysis scores of all axes. Convex hull areas, using axes 1 and 2 of the correspondence analysis, were calculated in RStudio 1.2.1335 (RStudio Team, 2015) using the package 'sp' 1.3-1 (Pebesma et al., 2018). Convex hull area was used as a measure of disparity and plotted alongside richness (i.e., number of artiodactyl species per fauna) using Numbers 6.1 .

\section{RESULTS}

\section{Analysis of Morphospace Occupation}

The correspondence analysis plots (Figure 4) show the morphospace positions on the first three principal axes of all taxa, including the extant ruminant artiodactyls from the presentday Serengeti and the fossil ruminant and camelid artiodactyls from the Neogene of North America. The resulting eigenvalues from the correspondence analysis are shown in Table 2 (for the row and column scores see Appendices 7 and 8). Euclidean similarity and distance indices between individual taxa can be found in the Supplementary Table S1, with values closer to zero indicating greater similarity/proximity in the morphospace and larger values indicating less similarity/proximity. Figure 4A shows the first two principal axes and Figure 4B shows axes 2 and 3; together these plots represent a three-dimensional morphospace seen from different vantage points. Axis one (Figure 4A) is dominated by body size and premolar row length and roughly arranges taxa in a continuum from large animals (e.g., giraffe, Giraffa camelopardalis, and common eland, Taurotragus oryx) with negative scores to small ones (e.g., duikers, genera Philantomba and Sylvicapra) with positive scores; additionally, taxa with shorter premolar rows have negative scores (e.g., camelids) and those with longer premolar rows have positive scores (e.g., most ruminants). Axis two (Figures 4A,B) is dominated by hypsodonty level and anterior face length: hypsodont mixed-feeders (e.g., impala, Aepyceros melampus; Grant's gazelle, Nanger granti; Thomson's gazelle, Eudorcas thomsonii) have negative scores (although the common eland has a slightly positive score), brachydont browsers have positive scores (e.g., giraffe and gerenuk, Litocranius walleri), and hypsodont grazers have scores close to zero (e.g., Bohor reedbuck, Redunca redunca; hartebeest, Alcelaphus buselaphus; African buffalo, Syncerus caffer). Axis three (Figure 4B) is dominated by the relative lengths of the temporalis moment arm and the

TABLE 2 | Correspondence analyses axes, eigenvalues and percent variation values for the sample comprising the extinct artiodactyl taxa from North America and the Serengeti fauna (excluding modern day camels).

\begin{tabular}{lccc}
\hline Axis & Eigenvalue & \% of total & Cumulative \\
\hline 1 & 0.0467617 & 35.686 & 35.686 \\
2 & 0.0318203 & 24.283 & 59.969 \\
3 & 0.0163164 & 12.452 & 72.421 \\
4 & 0.0142282 & 10.858 & 83.279 \\
5 & 0.0115209 & 8.7921 & 92.071 \\
6 & 0.00573469 & 4.3764 & 96.448 \\
7 & 0.00465464 & 3.5522 & 100
\end{tabular}




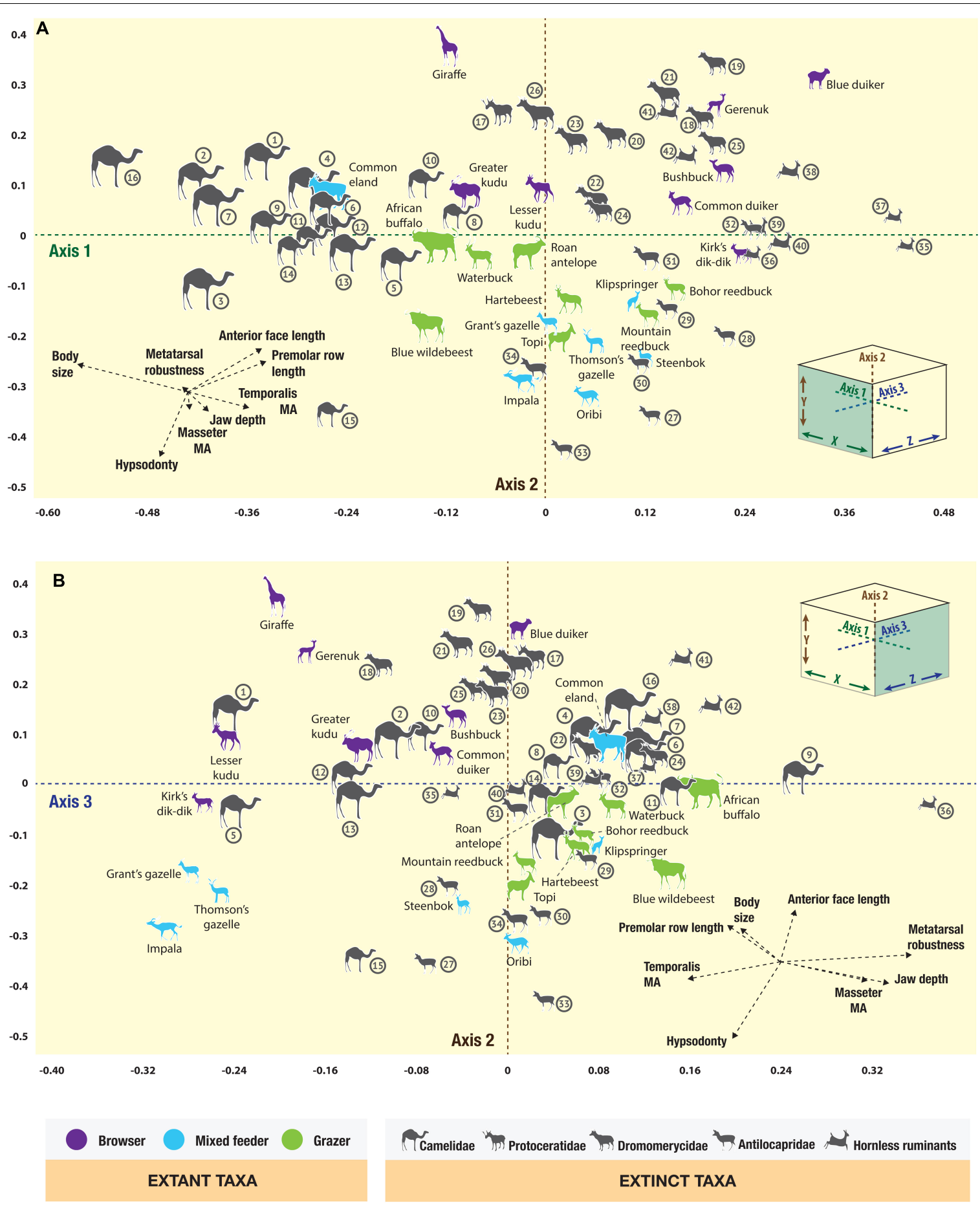

FIGURE 4 | Correspondence analysis plot of the artiodactyls from the Serengeti and from the Neogene of the Great Plains in North America, showing (A) axes one and two, (B) axes two and three. Camelidae: 1. Aepycamelus sp., 2. Alforjas magnifontis, 3. Camelops sp., 4. Gigantocamelus spatula, 5. Hemiauchenia sp., 6. Homocamelus sp., 7. Megatylopus sp., 8. Michenia sp., 9. Miolabis sp., 10. Oxydactylus sp., 11. Paramiolabis tenuis, 12. Pleiolama magnifontis, 13. Procamelus grandis, 14. Protolabis heterodontus, 15. Stenomylus sp., 16. Titanotylopus nebraskensis; Protoceratidae: 17. Lambdoceras sp.; Dromomerycidae: 18. Barbouromeryx sp., 19. Bouromeryx sp., 20. Cranioceras unicornis, 21. Dromomeryx sp., 22. Pediomeryx hemphilliensis, 23. Rakomeryx sp., 24. Sinclairomeryx riparius, 25. Subdromomeryx scotti, 26. Yumaceras figginsi; Antilocapridae: Subfamily Merycodontinae - 27. Cosoryx furcatus, 28. Merycodus sp., 29. Paracosoryx alticornis, 30. Paracosoryx wilsoni, 31. Ramoceros sp., 32. Submeryceros minor, Subfamily Antilocaprinae - 33. Capromeryx sp., 34. Texoceros guymonensis; Hornless ruminants, families Gelocidae: 35. Pseudoceras sp., Hypertragulidae: 36. Nanotragulus sp., Leptomerycidae: 37. Pseudoparablastomeryx sp., and Moschidae: 38. Blastomeryx elegans, 39. Blastomeryx gemmifer, 40. Longirostromeryx wellsi, 41. Parablastomeryx advena, 42. Problastomeryx sp. 
metatarsals, and to a lesser extent by the relative lengths of the masseter moment arm and jaw corpus depth.

The extant Serengeti ruminants are well-discriminated in the three-dimensional morphospace on the basis of their dietary categories (see Appendix 9 for a full breakdown of where the taxa plot in the 3D morphospace). Dietary groups are statistically different from one another (Table 3 ). Browsers predominantly plot toward the front (i.e., negative scores on axis three) and top (i.e., positive scores on axis two) of the morphospace, with the exception of the blue duiker (Philantomba monticola), which has a weakly positive score on axis three, and Kirk's dik-dik (Madoqua kirkii), which has a weakly negative score on axis two. Overall, browsers are spread out on the right-hand side of the morphospace (i.e., positive scores on axis one), with the exception of the largest browsers in the sample: the lesser and greater kudu (Tragelaphus imberbis and Tragelaphus strepsiceros, respectively), and the giraffe, which have weakly to moderately negative scores on axis one. Mixed feeders are very spread out on axis three but, overall, they tend to plot closer to the front of the morphospace (i.e., negative and weakly positive scores on axis three). They predominantly plot in the bottom (i.e., negative scores on axis two) right hand side (i.e., positive scores on axis one) area of the morphospace, with the exception of the common eland (weakly positive score on axis two and a strongly negative score on axis one) and the impala (weakly negative score on axis one). Grazers are fairly well-constrained in the three-dimensional morphospace. All of the grazing taxa plot in the back (i.e., positive scores on axis three) bottom (i.e., negative scores on axis two) area of the morphospace, and are evenly distributed between the left and right hand sides (i.e., moderately negative to moderately positive scores on axis one). In summary, the extant artiodactyl fauna from the Serengeti is welldiscriminated in this analysis in terms of body size and dietary category, and therefore can provide a suitable basis for inferring the ecomorphological characteristics of the extinct artiodactyls from the Neogene of North America.

The phylogenetic flexible discriminant analysis (phylo FDA) results plot (Figure 5) also shows good separation between all three dietary groups among extant taxa, but shows particularly good separation between grazers and the other two dietary groups. Grazers tend to have more positive discriminant axis one (DA1) scores and more negative DA2 scores, browsers tend to have more negative DA1 and DA2 scores, and mixed feeders tend to have more negative DA1 scores and more positive DA2 scores.

TABLE 3 | Summary of one-way PERMANOVAs run with all row scores obtained from the correspondence analysis (permutation $N=9999$ ) to test for differences between groups of interest.

\begin{tabular}{lc}
\hline & $\boldsymbol{p}$ values \\
\hline Extinct ruminants vs. extant ruminants & $\mathbf{0 . 0 6 3}$ \\
Extinct camelids vs. extinct ruminants & $\mathbf{0 . 0 0 1}$ \\
Extant ruminants: browsers vs. grazers & $\mathbf{0 . 0 0 3}$ \\
Extant ruminants: browsers vs. mixed feeders & $\mathbf{0 . 0 0 2 6}$ \\
Extant ruminants: mixed feeders vs. grazers & $\mathbf{0 . 0 0 5 8}$ \\
\hline Statistically significant $p$ values $(p<0.05)$ in cells shaded in vellow.
\end{tabular}

Statistically significant $p$ values $(p<0.05)$ in cells shaded in yellow.
The posterior probability and discriminant axis values for all taxa are presented in Appendix 10.

The extinct camelids plot on the left hand side of the correspondence analysis plot (Figure 4, i.e., negative scores on axis one), in both the front and back of the morphospace (i.e., ranging from strong negative scores to strong positive scores on axis three). Overall, camelids tend to plot toward the middle of the morphospace (i.e., weakly negative to weakly positive scores on axis two), although Stenomylus has a strongly negative score on axis two. A number of camelids plot outside the area of morphospace occupied by any modern artiodactyl (e.g., Camelops sp., Stenomylus sp., Titanotylopus sp.), but some of them plot near the greater kudu (e.g., Procamelus grandis, Pleiolama magnifontis, and Oxydactylus sp.; Euclidean distances range from 0.330 to 0.363 ), the common eland (e.g., Homocamelus sp., Megatylopus sp.; Euclidean distances: 0.182 and 0.186 , respectively), or the roan antelope (Hippotragus equinus) and waterbuck (Kobus ellipsiprymnus) (e.g., Paramiolabis sp., Homocamelus sp., Michenia sp.; Euclidean distances range from 0.239 to 0.352 ). The posterior probability obtained from the phylogenetic flexible discriminant analysis classifies most camelids as mixed feeders (Figure 5), with the exception of Aepycamelus, Oxydactylus and Procamelus (classified as browsers), as well as Camelops and Gigantocamelus (classified as grazers).

The sole representative of the family Protoceratidae, Lambdoceras sp., plots in the back (i.e., positive score on axis three), top (i.e., positive score on axis two), left hand side (i.e., negative score on axis one) octant of the morphospace, near extant browsers (Figure 4). Lambdoceras is classified as a browser in Figure 5.

For the most part, dromomerycids plot in the front (i.e., negative scores on axis three), top (i.e., positive scores on axis two), right hand side (i.e., positive scores on axis one) of the morphospace (Figure 4), with the exception of Yumaceras (a weakly positive score on axis three and a weakly negative score on axis one), and Pediomeryx and Sinclairomeryx (weakly positive scores on axis one and weakly to moderately positive scores on axis three). Overall, members of the Dromomerycidae plot close together in an area of the morphospace that somewhat resembles that occupied by medium-to-small to medium-sized browsers like the gerenuk, bushbuck (Tragelaphus scriptus), common duiker (Sylvicapra grimmia), and blue duiker. Most dromomerycids, except for Sinclairomeryx and Pediomeryx, are classified as browsers as shown in Figure 5.

The pronghorns (family Antilocapridae) predominantly plot in the back (i.e., positive scores on axis three), bottom (i.e., negative scores on axis two), right hand side (i.e., positive scores on axis one) octant of the morphospace (Figure 4), with the exception of Cosoryx furcatus and Merycodus (weakly positive scores on axis three), Submeryceros (a weakly positive score on axis two) and Texoceros (a weakly negative score on axis one). Merycodontine antilocaprids (an extinct subfamily of small forms) such as Cosoryx furcatus, Merycodus necatus and Paracosoryx sp., and the antilocaprine antilocaprids Capromeryx sp. and Texoceros sp., plot closely with mixedfeeding taxa such as the oribi (Ourebia oribi) and the steenbok 


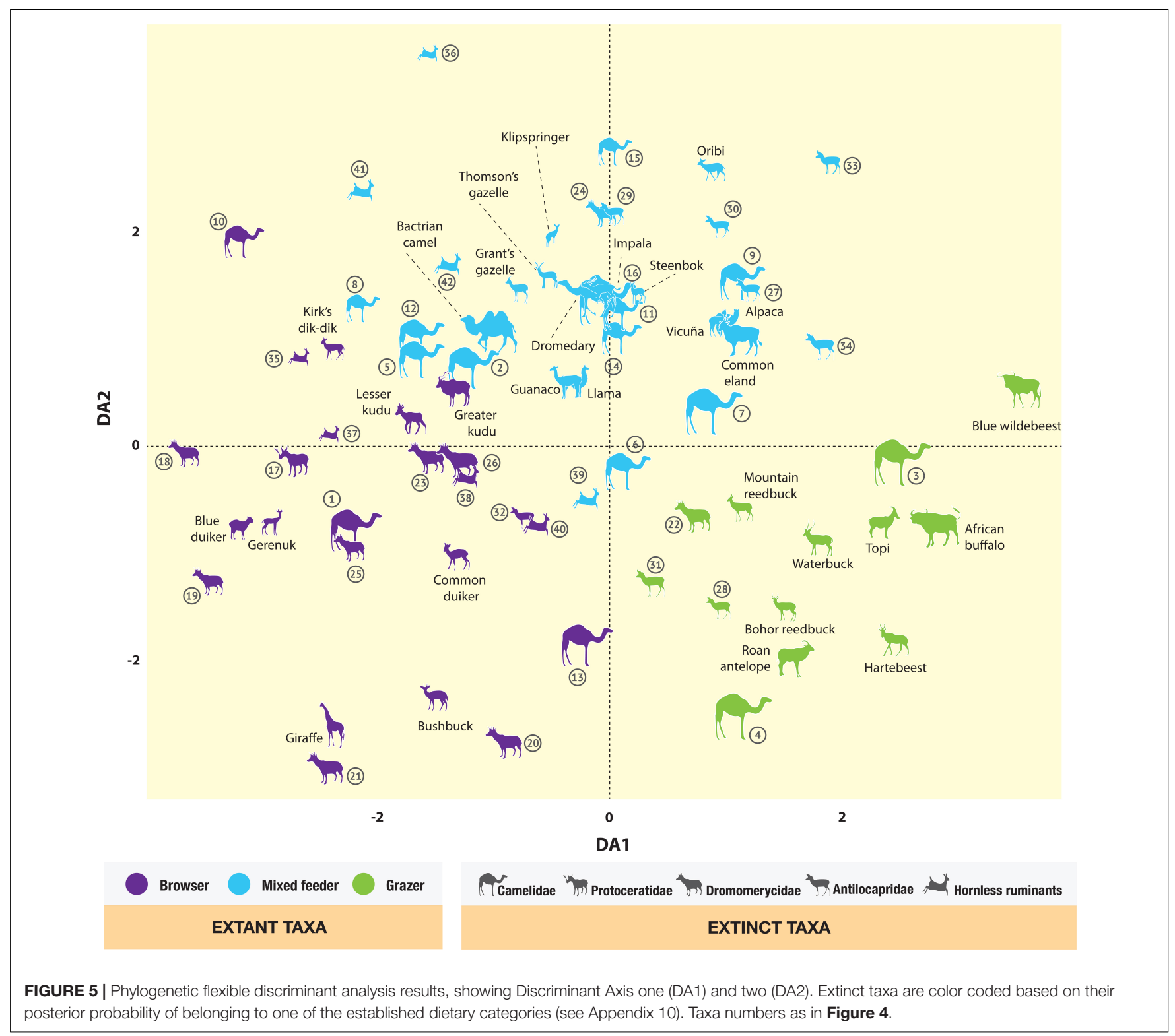

(Raphicerus campestris), and with grazers such as the topi (Damaliscus lunatus) and the mountain reedbuck (Redunca fulvorufula) (Euclidean distances range from 0.190 to 0.338). The merycodontines Ramoceros sp. and Submeryceros sp. plot closer to the middle of axis two, somewhat near the Bohor reedbuck (Euclidean distances: 0.187 and 0.190, respectively). The phylogenetic flexible discriminant analysis classifies most pronghorns as mixed feeders, with the exception of Submeryceros (classified as a browser), and Merycodus and Ramoceros (classified as grazers) (Figure 5).

Among the hornless ruminants (all small taxa), Pseudoceras (family Gelocidae) plots in the front (negative score on axis three), bottom (negative score on axis two), right hand side (positive score on axis one) octant of the morphospace (Figure 4). The remainder of the hornless ruminants plot in the back (positive scores on axis three), right hand side (positive scores on axis one) area of the morphospace, with most taxa plotting in the top octant (positive scores on axis two), with the exception of Nanotragulus (family Hypertragulidae) and Longirostromeryx (family Moschidae, extinct subfamily Blastomerycinae), which have weakly negative scores on axis two. In general, the small hornless ruminants occupy an area of the morphospace unoccupied by any extant ruminants. The moschid Longirostromeryx wellsi plots somewhat near the small extant browsers, particularly the bushbuck and the common duiker (Euclidean distances: 0.209 and 0.326, respectively). Most hornless ruminants are classified as browsers in Figure 5, except for Nanotragulus, Blastomeryx gemmifer, Parablastomeryx, and Problastomeryx which are classified as mixed feeders.

Most extinct and extant artiodactyl families are statistically different from one another (Table 4), except for dromomerycids and moschids. Interestingly, extinct and extant ruminants are 
TABLE 4 | Summary of one way PERMANOVAs run with all row scores obtained from the correspondence analysis (permutation $N=9999$ ) to test for differences between families (Bovidae includes only extant taxa, while all the other families include only extinct taxa).

\begin{tabular}{|c|c|c|c|c|c|}
\hline Family & Bovidae & Camelidae & Dromomerycidae & Antilocapridae & Moschidae \\
\hline \multicolumn{6}{|l|}{ Bovidae } \\
\hline Camelidae & 0.0001 & & & & \\
\hline Dromomerycidae & 0.001 & 0.0001 & & & \\
\hline Antilocapridae & 0.027 & 0.0001 & 0.0001 & & \\
\hline Moschidae & 0.0053 & 0.0001 & 0.102 & 0.0045 & \\
\hline
\end{tabular}

Statistically significant $p$ values $(p<0.05)$ in cells shaded in yellow.

also statistically different from one another on the basis of their ecologically relevant morphological characters (Table 3), most likely because the extant ruminants are largely bovids.

\section{Morphospace Occupation Changes Through Time}

Figure 6A shows the changes in morphospace occupation of artiodactyl communities in the Central Great Plains of North America from the early Miocene (Arikareaan 4) to the earliest Pleistocene (late Blancan) (axis one vs. axis two plots on the left, axis three vs. axis two plots on the right), and illustrates the prevailing conditions of temperature and precipitation during the transition from savanna woodlands (dominated by pooid grasses) into grass-dominated ecosystems. For the morphospace occupation plots of the individual faunas, showing how the individual taxa plot within the overall morphospace, see Appendix 11. The most taxonomically diverse faunas, which occupied the largest volumes of morphospace (Table 5 and Figure 7) across axes one, two and three (i.e., 3-Thomson Quarry, 4-Echo Quarry, 5-Norden Bridge Quarry, 6-Burge Quarry) - were from late early Miocene to the middle Miocene localities. During this time [the Middle Miocene Climatic Optimum, which represents the peak of the Miocene warming period between 17 and $15 \mathrm{Ma}$; Zachos et al. (2001)], high temperatures and precipitation levels were evident. In contrast, the faunas spanning the late Miocene to the earliest Pleistocene (i.e., 7-Blue Jay Quarry, 8-Cambridge Local Fauna, 9-Edson Quarry, 10-Broadwater Local Fauna, and 11-Big Springs Local fauna) were comparatively less diverse, their morphospace occupancy was significantly smaller (with the exception of 8-Cambridge Local Fauna, whose morphospace occupation area was one of the largest in the study with respect to the first two axes, even though the fauna was not very diverse), and they tend to plot more negatively on axes one and three. The prevailing environmental conditions of the time were characterized by low mean annual temperatures and precipitation levels, which started with the Mid-Miocene Climate Transition (marked by the formation of the East Antarctic ice sheet at around $14 \mathrm{Ma}$ and a concomitant decrease in temperatures) (Flowers and Kennett, 1993; Pierce et al., 2017).

Throughout the Neogene, mixed feeders were common in all artiodactyl faunas. During the mid-Miocene (specifically from the Hemingfordian to the Clarendonian), artiodactyl faunas were rich in browsing taxa (including many dromomerycids and hornless ruminants, and some camelids). Toward the late Miocene, the diversity of browsers started declining, until ultimately mixed-feeding taxa (and possibly some grazers) were all that remained.

The results of the phylogenetic flexible discriminant analysis indicate a change in diet among camelids throughout the Neogene: during the middle Miocene camelids were browsers and mixed feeders, toward the end of the Miocene they were exclusively mixed feeders, and by the Pliocene a couple of taxa possibly could have been grazers. We do not see a marked change in diet among individual ruminant groups through time, partly because they were neither as diverse nor as long lived as camelids. Some hornless ruminants (i.e., gelocids and leptomerycids) and most dromomerycids remained browsers (with the exception of Pediomeryx) throughout the Neogene, and pronghorns were mostly mixed feeders. All of these families decreased in diversity after the Mid-Miocene Climatic Optimum and went extinct by the end of the Miocene [in the Pliocene the role of browsing artiodactyls was taken by immigrant cervids Webb, 1998a)].

Figure 6A depicts the differential morphospace occupation of camelids and ruminants from localities in different NALMA subdivisions throughout the Neogene. In broad terms, the morphospace occupation of camelids and ruminants does not overlap along axis one; ruminants tend to occupy a larger morphospace area than camelids in all time periods except the late Blancan. However, while ruminants comprised several families and camelids only one, throughout the Neogene camelids were always more diverse than any individual ruminant family [except in the early Hemingfordian Flint Hill Local Fauna fauna No. 2; see Appendix 3)].

Figure 6B compares the morphospace occupation of the most diverse Neogene fauna in the study, Burge Quarry (fauna No. 6; bottom), with the extant Serengeti ruminants (top). The morphospace occupation of extant camelids (not present in the Serengeti) is also shown. In both extinct and extant faunas, camelids tend to plot toward the left-hand side of the plot (negative scores on axis one) and ruminants plot toward the right-hand side of the plot (positive scores on axis one). While the morphospace occupation of camelids and ruminants does not overlap in the extinct fauna, it does among the extant taxa: lamines plot near extant grazers and medium-sized mixed feeding bovids, and camelines plot near the common eland. Some modern ruminants also occupy areas of morphospace not occupied by their extinct counterparts (but remember that no Neogene North American ruminants were bovids), such 
A Morphospace occupation

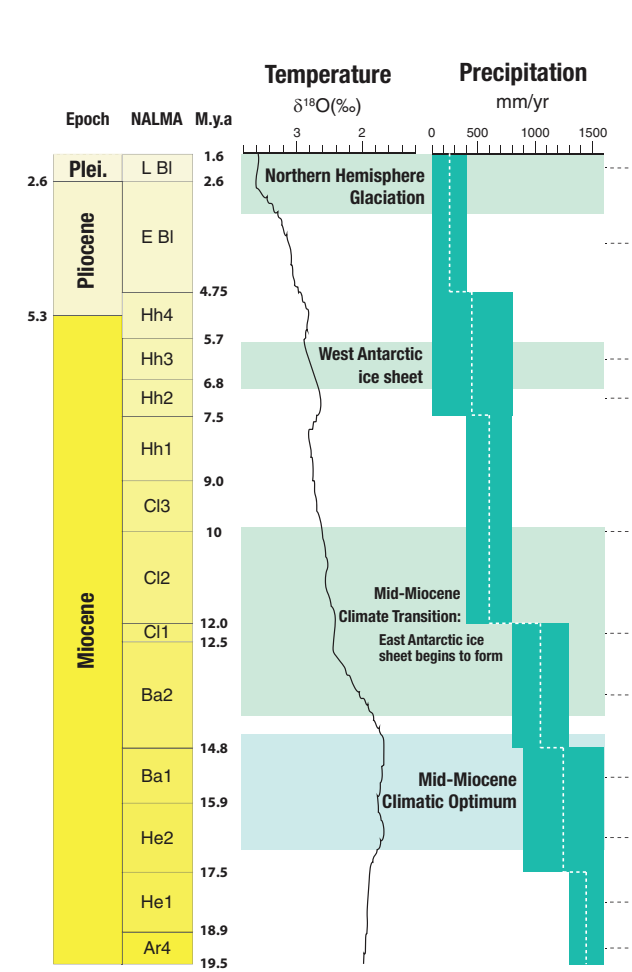

B

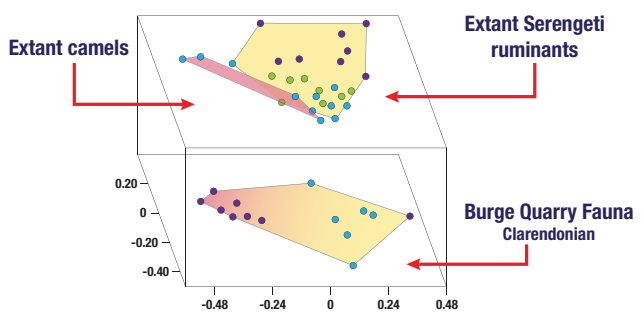

per fauna

per fauna

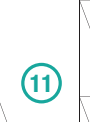

(10)

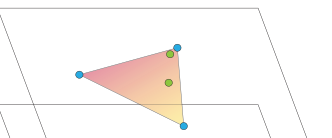

(9)

(8)

(7)
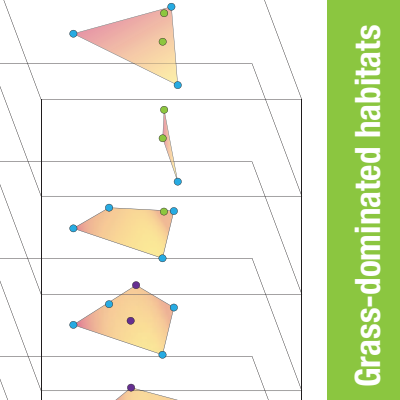

(6)

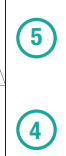

(4)

(3)
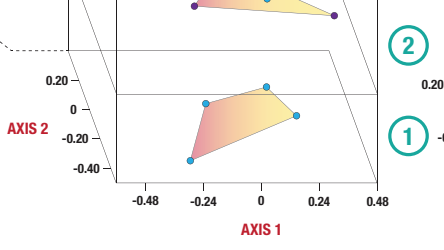

(2)

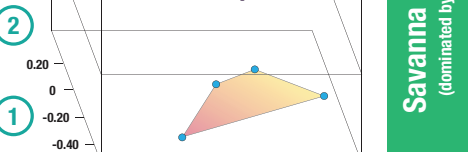

FIGURE 6 | (A) Changes in morphospace occupation throughout the Neogene of ruminant and camelid artiodactyl faunas from the Central Great Plains of North America in comparison to the then prevailing environmental conditions. $\delta^{18} \mathrm{O}$ values used as a proxy for mean annual global temperature (from Zachos et al., 2001). Precipitation values from the Great Plains are displayed in $\mathrm{mm} /$ year (from Eronen et al., 2012). Convex hulls show morphospace occupation of ungulate faunas: pink areas denote camel morphospace and yellow areas ruminant morphospace. Locality numbers as in Figure 2. Axes of morphospace plots as in Figure 4A (on the left) and Figure 4B (on the right). (B) Comparison between the morphospace occupation (axes one and two) of the most diverse Neogene North American fauna (Burge Quarry [Clarendonian]), the extant ruminant Serengeti fauna, and the extant camelids. Proposed dietary categories of extinct taxa obtained from the results of the phylogenetic flexible discriminant analysis (shown in Figure 5).

as the blue duiker and large grazers like the African buffalo and the blue wildebeest. Likewise, extant camelids occupy areas of morphospace not occupied by Neogene North American camelids; for example, lamines have more positive scores on axis one and overlap with the ruminant morphospace. This indicates that, even though there is a phylogenetic component to the morphospace occupation of camelids and ruminants, overlap is not absent, suggesting that there is an ecomorphological signal in addition to a phylogenetic one.

Throughout the Neogene, most artiodactyl faunas were ecomorphologically similar to one another (Table 6), with a few exceptions. Flint Hill Local Fauna (fauna No. 2), dominated by ruminants and scarce in camelids, is statistically different to faunas 7-Blue Jay Quarry, 9-Edson Quarry, 10-Broadwater Local Fauna, and 11-Big Springs Local fauna (dominated by camelids and with few ruminants). Likewise, Big Springs Local Fauna (fauna No. 11- low diversity and disparity) is statistically different to faunas 3-Thomson Quarry and 5-Norden Bridge Quarry (very diverse and disparate faunas). When comparing the Neogene faunas with the extant Serengeti fauna, almost $50 \%$ of the former are statistically different from the modern African assemblage, namely faunas 2- Flint Hill Local Fauna, 7Blue Jay Quarry, 9-Edson Quarry, 10-Broadwater Local Fauna, and 11-Big Springs Local fauna, which represent some of the 
TABLE 5 | Disparity and diversity of the faunas of the Neogene of North America.

\begin{tabular}{|c|c|c|c|c|}
\hline & Fauna & NALMA & Convex hull area (first two axes) & Number of species \\
\hline 1 & Morava Ranch Quarry, Marsland Formation & Ar4 & 0.1073165 & 4 \\
\hline 2 & Flint Hill Local Fauna, Batesland Formation & He1 & 0.068118 & 6 \\
\hline 3 & Thomson Quarry, Sheep Creek Formation & $\mathrm{He} 2$ & 0.237546 & 13 \\
\hline 4 & Echo Quarry, Olcott Formation & Ba1 & 0.216306 & 14 \\
\hline 5 & Norden Bridge Quarry Local Fauna, Valentine Formation & $\mathrm{Ba} 2$ & 0.250053 & 11 \\
\hline 6 & Burge Quarry Fauna, Valentine Formation & $\mathrm{Cl} 1$ & 0.2500045 & 14 \\
\hline 7 & Blue Jay Quarry, Ash Hollow Formation & $\mathrm{Cl} 2-3$ & 0.036414 & 5 \\
\hline 8 & Cambridge Local Fauna (Ft-40), Ash Hollow Formation & Hh2 & 0.220803 & 6 \\
\hline 9 & Edson Quarry Fauna, Ogallala Formation & Hh3 & 0.08421 & 5 \\
\hline 10 & Broadwater Local Fauna & $\mathrm{EBl}$ & 0.064633 & 3 \\
\hline 11 & Big Springs Local Fauna & $\mathrm{LBI}$ & 0.0958535 & 5 \\
\hline
\end{tabular}

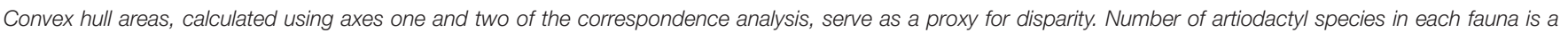
proxy for diversity.

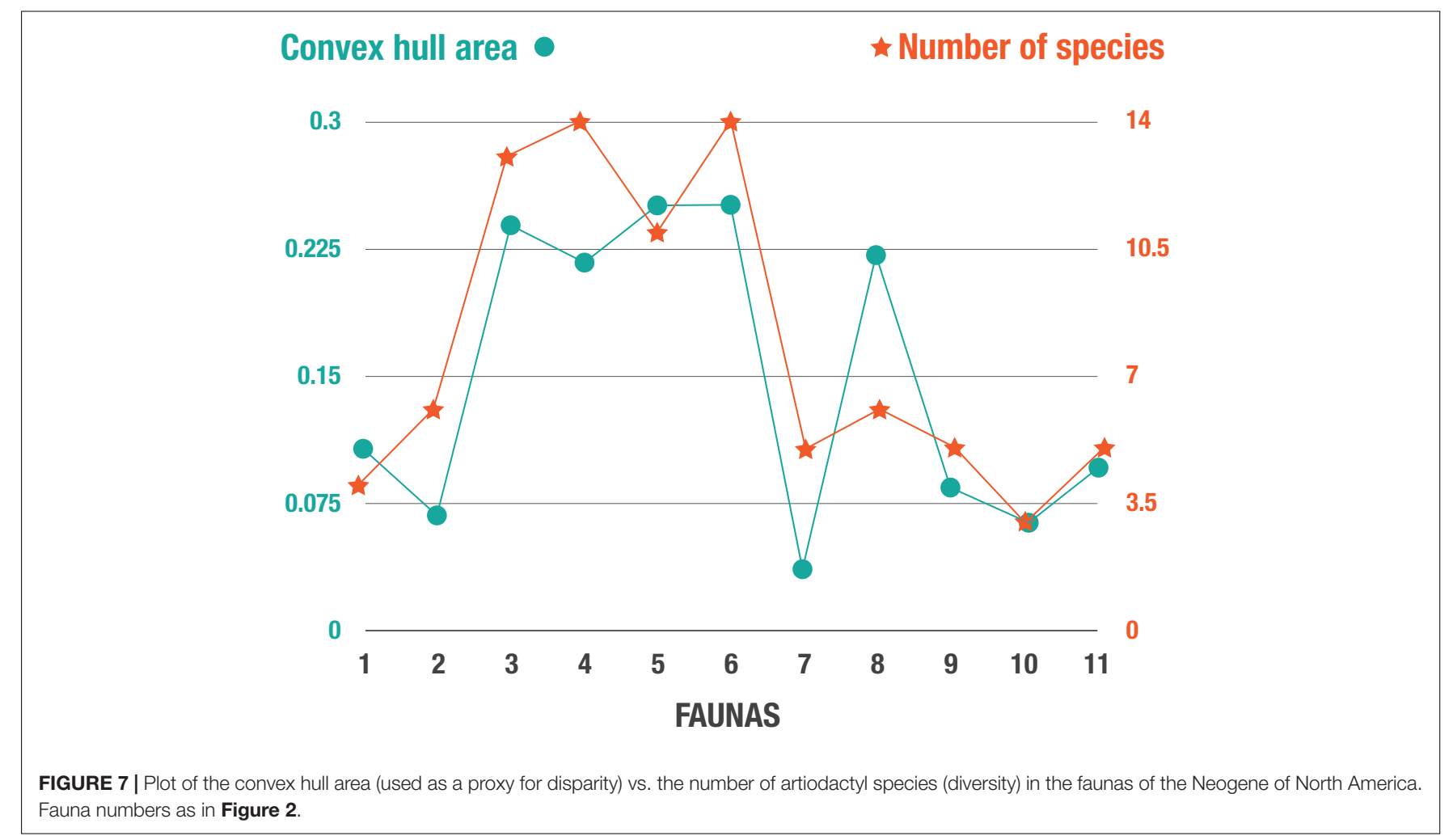

least disparate and diverse faunas (with the exception of fauna 1-Morava Ranch Quarry).

\section{DISCUSSION}

\section{Comparative Morphospace Occupation Camelidae}

During the Cenozoic of North America, the family Camelidae was taxonomically and ecologically diverse (Honey et al., 1998): some taxa have even been compared to modernday African artiodactyls, including the gazelle-like Stenomylus, the gerenuk-like Oxydactylus, and the giraffe-like Aepycamelus
(Honey et al., 1998). This family has teeth that range from brachydont (e.g., Oxydactylus) to highly hypsodont (e.g., Stenomylus), and their limbs range from relatively short (e.g., miolabines and derived protolabines) to extremely long (e.g., Oxydactylus and Aepycamelus) (Honey et al., 1998). Mesowear, microwear and premaxillary shape analyses suggest that most camelids were browsers or mixed feeders (Dompierre and Churcher, 1996; Semprebon and Rivals, 2010; Fraser and Theodor, 2013; Semprebon et al., 2019). Except for two individuals identified as Hemiauchenia sp. and Megatylopus sp., from late Hemphillian localities in Arizona, camelids do not appear to have been grazers (Appendix 12: Semprebon and Rivals, 2010; Semprebon et al., 2019). As previously mentioned, 
TABLE 6 | Summary of one way PERMANOVAs run with all row scores obtained from the correspondence analysis (permutation $N=9999$ ) to test for differences between the modern-day Serengeti (here labeled fauna S) and Neogene faunas, as well as between Neogene faunas.

\begin{tabular}{|c|c|c|c|c|c|c|c|c|c|c|c|c|}
\hline Faunas & $\mathbf{S}$ & 1 & 2 & 3 & 4 & 5 & 6 & 7 & 8 & 9 & 10 & 11 \\
\hline \multicolumn{13}{|l|}{$S$} \\
\hline 1 & 0.0717 & & & & & & & & & & & \\
\hline 2 & 0.0116 & 0.3046 & & & & & & & & & & \\
\hline 3 & 0.3255 & 0.3337 & 0.2422 & & & & & & & & & \\
\hline 4 & 0.0575 & 0.1772 & 0.133 & 0.9556 & & & & & & & & \\
\hline 5 & 0.4926 & 0.242 & 0.3559 & 0.9739 & 0.7242 & & & & & & & \\
\hline 6 & 0.4989 & 0.2268 & 0.0709 & 0.8187 & 0.6691 & 0.6104 & & & & & & \\
\hline 7 & 0.0045 & 0.1299 & 0.0293 & 0.1403 & 0.3488 & 0.107 & 0.2777 & & & & & \\
\hline 8 & 0.1579 & 0.1688 & 0.1054 & 0.347 & 0.4031 & 0.34 & 0.7956 & 0.6375 & & & & \\
\hline 9 & 0.0206 & 0.0611 & 0.0194 & 0.1207 & 0.1903 & 0.1203 & 0.4145 & 0.6328 & 0.9972 & & & \\
\hline 10 & 0.0318 & 0.3139 & 0.0131 & 0.1534 & 0.1684 & 0.1486 & 0.2955 & 0.4042 & 0.5219 & 0.5565 & & \\
\hline 11 & 0.0029 & 0.0932 & 0.0086 & 0.0357 & 0.0668 & 0.0414 & 0.1419 & 0.73 & 0.5658 & 0.8922 & 0.8549 & \\
\hline
\end{tabular}

Statistically significant $p$ values $(p<0.05)$ in cells shaded in yellow. Neogene faunas numbers as in Figure 2.

our phylogenetic flexible discriminant analysis (Figure 5) classified most camelids as mixed feeders, with the exception of Aepycamelus, Oxydactylus, and Procamelus (classified as browsers), and Camelops and Gigantocamelus (classified as grazers). Janis et al. (1994) concluded that very few camels appear to have been true browsers (on the basis of craniodental morphology), so there is some disagreement with the microwear analysis results of Semprebon and Rivals (2010), which suggest that most camelids were browsers. These different results might be due to the fact that microwear can be very variable, because it most likely reflects the last meal of the animal (Solounias and Semprebon, 2002).

The position of the camelids in the morphospace is reflective of their phylogeny to some degree; as previously discussed, however, their position is likely not entirely due to phylogeny, and may indeed reflect ecological differences between extinct camelids and African bovids (see also Figure 6B). While there are some similarities between the extinct camelids and the extant artiodactyls, most extinct camelids do not plot within the morphospace of the extant taxa; rather, they mostly cluster on the left-hand side of the plot, with negative scores on axis one (Figure 4A). It is notable that, while Figure 4B shows camelids clustering with extinct ruminants along axes two and three, in the three-dimensional morphospace they largely plot away from each other based on characters like premolar row length and other characters that plot along axis one (see Appendix 9). However, this clustering in the plane defined by axes two and three is still relevant: it shows that camelids and ruminants share some characteristics, such as hypsodonty levels that range from brachydont to hypsodont, and metatarsals that range from slender to robust. An additional correspondence analysis (Appendix 13, see also Figure 5B), including extant camelids places the lamines within the three-dimensional ruminant morphospace (although the camelines plot with many of the extinct camelids). This indicates that the position of the extinct camelids does not simply reflect phylogenetic differences from extant ruminants. When phylogeny is taken into account (as shown in the phylogenetic flexible discriminant analysis,
Figure 5), camelids are usually classified as mixed feeders much like the extant common eland, and plot close to this taxon in morphospace.

The extinct camelids plot separately from the ruminants in the analysis mainly because of their comparatively large body sizes and shorter premolar row (Figure 4A). A relatively short premolar row is characteristic of the family Camelidae as a whole (Honey et al., 1998), but is also characteristic of mixed feeders and grazers among ruminants (Janis, 1995). Some taxa (e.g., Gigantocamelus, Homocamelus, Megatylopus, and Michenia) plot close to large sized mixed feeders and grazers, such as the common eland, the wildebeest and the waterbuck (Euclidean distances range from 0.182 to 0.409 ). Their broad spread along axis three is largely due to the variable length of their temporalis moment arm, probably associated with differences in the toughness of the food ingested by the different taxa (Janis, 1990, 1995; Pérez-Barbería and Gordon, 1999; Mendoza et al., 2002), as well as to their relative metatarsal length, reflective of differences in habitat preference and cursoriality (Scott, 1985). Their position toward the middle of axis two, with weakly negative to weakly positive scores, reflects the predominance of mesodont teeth among camelids, commonly seen in mixedfeeding taxa (Janis and Fortelius, 1988; Damuth and Janis, 2011; Fraser and Theodor, 2011), and short anterior faces, commonly seen in browsers and some mixed feeders (Janis, 1995; Clauss et al., 2008).

An outlier from the main area of camelid clustering is the highly hypsodont, gazelle-like Stenomylus, with a weakly negative score on axis one and a highly negative score on axis two. The impala and Grant's gazelle are the extant taxa to which it falls closest in the morphospace (Euclidean distances: 0.382 and 0.479 , respectively), and both are open-habitat dwellers, as previously suggested for Stenomylus (Honey et al., 1998). The separation of Stenomylus from "camelid morphospace" and its relative proximity to extant mixed-feeding medium-sized bovids, indicates that the morphospace occupation of camelids is not constrained solely by phylogeny: a true ecological signal is reflected here. The long-legged "giraffe camels," namely the 
medium-sized Oxydactylus and the large-sized Aepycamelus, plot relatively close to each other, with negative scores on axis one and weakly positive scores on axis two; however, Aepycamelus scores more negatively on axes one and three, due to its larger premolar row length, larger body size, longer temporalis moment arm, and relatively more slender metatarsals. Similarly, extremely slender metatarsals can be found in other camelids like Hemiauchenia, Protolabis, and Stenomylus, and in extant ruminants such as the giraffe, gerenuk, and impala. Aepycamelus is frequently compared with the extant giraffe, and plots relatively close to it on axis three (see Figure 4). While both taxa have extremely slender metatarsals, Aepycamelus has a shorter face, higher-crowned teeth, and is smaller. The Euclidean distance measurement between these two taxa is 0.374 ; other extant taxa that also plot relatively close to Aepycamelus include the greater kudu, the common eland, and the lesser kudu (Euclidean distances: 0.345, 0.374 , and 0.376 , respectively).

\section{Protoceratidae}

Lambdoceras, the last protoceratid remaining in the Great Plains during the Neogene, has been regarded as a deer-like tree browser (Prothero, 1998). The family Protoceratidae has relatively lowcrowned teeth (brachydont to sub-mesodont) (Prothero, 1998) and relatively short metapodials (Frick, 1937), which alongside other characteristics (e.g., retracted nasals indicative of a mooselike proboscis, and a persistent four-toed manus) might indicate that protoceratids were deep-forest-dwelling forms like the extant moose, Alces alces, or the bushbuck (Janis, 1982; Webb et al., 2003; Prothero and Ludtke, 2007). Microwear suggests that Lambdoceras consumed leaves and fruits (Prothero and Ludtke, 2007). In this analysis Lambdoceras plots in the back, top, left octant of the morphospace, with a negative score on axis one and a positive score on axes two and three. This protoceratid does not plot close to any particular extant taxon (it is closest to the bushbuck; Euclidean distance: 0.383 ), but it does plot near the morphospace of extant browsers. The position of Lambdoceras within the extant browser morphospace reflects its relatively large body size, similar to that of the lesser kudu. The phylogenetic flexible discriminant analysis results are consistent with the interpretation that Lambdoceras is a browser.

\section{Dromomerycidae}

Dromomerycids have been interpreted as ecologically similar to either cervids or tragelaphine antelope (Janis and Manning, 1998b). Dromomerycids mostly have brachydont teeth and relatively short metapodials, indicative of closed habitats, although the members of the subfamily Aletomerycinae (represented here by Sinclairomeryx) were a little more hypsodont and had somewhat proportionally longer legs, probably reflecting a more open habitat lifestyle, and the later members of the Cranioceratini (Yumaceras and Pediomeryx) were also more hypsodont (Janis and Manning, 1998b). Craniodental and tooth wear studies show that they were browsers or mixed feeders (Semprebon et al., 2004). In this analysis they mainly cluster in the front, top, right hand side octant of the morphospace. A similar part of the morphospace is occupied by extant small to medium-sized browsing bovids, taxa with which dromomerycids share a long premolar row, brachydont to mesodont teeth, medium to long anterior faces, and relatively slender metatarsals; however, dromomerycids tend to be larger overall than most African browsing bovids (especially Yumaceras, which is similar in size to large antelope such as the greater kudu and roan antelope: Janis et al., 1994). The phylogenetic flexible discriminant analysis classifies Sinclairomeryx as a mixed feeder (in agreement with Janis and Manning, 1998b and Semprebon et al., 2004) and Pediomeryx as a grazer, probably reflecting their more open-habitat lifestyles. The diet of Pediomeryx is thought to have included a greater fibrous component than that of other dromomerycids (Janis and Manning, 1998b).

\section{Antilocapridae}

Within the family Antilocapridae, the members of the subfamily Merycodontinae have been interpreted as being typically solitary and ecotonal, akin to neotragine antelope (represented in this study by the steenbok, oribi, dik-dik, and klipspringer); on the other hand, members of the subfamily Antilocaprinae, which are more hypsodont and have relatively longer legs than merycodontines, have been interpreted as being more similar to herd-forming, open-habitat dwelling gazelles (Janis and Manning, 1998a). All members of the family Antilocapridae have been suggested as having a mixed feeding style on the basis of their narrow muzzle and high degree of hypsodonty (Janis and Manning, 1998a). Microwear and mesowear analyses indicate that while both subfamilies of antilocaprids seasonally incorporated some grass in their diets, antilocaprines ingested a higher proportion of grass than merycodontines (Semprebon and Rivals, 2007). In this analysis they mainly cluster in the back, bottom, right hand side octant of the morphospace, with positive scores on axes one and three and negative scores on axis two, similar to extant small mixed feeders and medium sized grazers. Their position in the morphospace is reflective of their small body sizes (similar to the oribi and steenbok), mesodont to highly hypsodont cheek teeth, long temporalis moment arms, and variably long anterior faces (characteristic of mixed feeding to grazing taxa), as well as their slender metapodials, often seen in open-habitat dwellers (Scott, 1985). Antilocaprines (i.e., Capromeryx and Texoceros) have often been compared with extant gazelles on the basis of their degree of hypsodonty, cranial morphology and metapodial proportions (Janis and Manning, 1998a); however, in this analysis they do not plot close to gazelles, which have relatively shallower jaws and relatively more slender metatarsals. The phylogenetic flexible discriminant analysis classifies most antilocaprids in the sample, including both antilocaprines, as mixed feeders, such as the extant gazelle. Two merycodontines are classified as grazers (Merycodus and Ramoceros), and one as a browser (Submeryceros); these three taxa have previously been considered mixed feeders. The unusual position in which they plot in Figure 5 might be reflective of their relatively long anterior faces.

\section{Hornless Ruminants}

Pseudoceras, one of only two genera of North American gelocids (the other being Floridameryx), has been interpreted 
as ecologically similar to the extant musk deer, Moschus, on the basis of its dentition and skeletal proportions (Métais and Vislobokova, 2007; Webb, 2008). Paleoecological evidence from a rich fossiliferous site in Florida suggests that this basal ruminant dwelled in aquatic and forested environments, very much like the extant African water chevrotain, Hyemoschus (Webb, 1998b). This small hornless ruminant has brachydont (Fraser and Theodor, 2013) to mesodont (Webb, 2008) teeth and relatively slender metapodials. Mesowear analyses of Pseudoceras skinneri from the Hemphillian of Texas and Nebraska suggest a browsing diet for this gelocid, while microwear analyses point to a more mixed feeding diet (Fraser and Theodor, 2013). In this analysis Pseudoceras is located in the front, bottom right hand side octant of the plot, which reflects its small size, long premolar row, extremely long coronoid process, and slender metatarsals. Pseudoceras plots near the morphospace of extant browsing ruminants, including Kirk's dik-dik and the common duiker (Euclidean distances: 0.410 and 0.415 , respectively). Pseudoceras is also classified as a browser by the phylogenetic flexible discriminant analysis.

The basal ruminant (traguloid) families Hypertragulidae and Leptomerycidae (represented here by Nanotragulus and Pseudoparablastomeryx, respectively), have been interpreted as being ecologically similar to their closest extant relatives, the family Tragulidae (i.e., the chevrotain, Hyemoschus, and the mouse-deer, Tragulus and Moschiola) (Webb, 1998b; Métais and Vislobokova, 2007). The members of these extinct families have brachydont teeth and shorter forelimbs than hindlimbs, suggesting that they might have been browsers living in forested settings with a rabbit-like bounding mode of locomotion (Webb, 1998b; Métais and Vislobokova, 2007). Very much like Pseudoceras, Pseudoparablastomeryx plots near the morphospace of extant browsers, but its extremely small size and very long coronoid process (and thus temporalis moment arm) prevent it from being closely comparable to any extant taxon (it falls closest to the common duiker; Euclidean distance: 0.408). Nanotragulus, due to its moderate temporalis moment arm and relatively medium-length metatarsals, plots completely outside the morphospace of extant browsers and it is not comparable to any extant taxon (it falls closest to the klipspringer; Euclidean distance: 0.452 ); the phylogenetic flexible discriminant analysis classifies it firmly as a mixed feeder (posterior probability $=99.74 \%$ ).

The extinct members of the family Moschidae have been interpreted as ecologically similar to extant moschids, the musk deer (Moschus) (Webb, 1998b). The taxa considered in this analysis constitute an endemic North American radiation of moschids: the blastomerycines (Métais and Vislobokova, 2007). This subfamily has brachydont to mesodont teeth (Webb, 1998b) and equal-length forelimbs and hindlimbs, the latter feature suggesting deer-like running and leaping habits unlike hypertragulids and leptomerycids (Webb, 1998b). Based on the dentition and known habits of the extant musk deer, blastomerycines (except Longirostromeryx) have been interpreted as being mixed feeders with a tendency toward browsing, living in densely vegetated environments and forest edges (Webb, 1998b). On the other hand, Longirostromeryx has been traditionally hypothesized to have been a mixed feeder with a coarser diet and more open habitat preferences, based on its skull and limb morphology (Webb, 1998b). However, a study by Chen (2015), using postcranial elements, suggests that Longirostromeryx was better suited to forested environments and that the more "primitive" Parablastomeryx in fact displayed adaptations for living in semi-open habitats. Our results show that, in general, blastomerycines plot close to the morphospace of extant small browsers, but tend to have relatively shorter premolar rows. Based on the results of the phylogenetic flexible discriminant analysis, we agree with Chen (2015): we found that Problastomeryx and Parablastomeryx were classified as mixed feeders, while Blastomeryx elegans and Longirostromeryx were classified as browsers. All the blastomerycine taxa in our analysis had relatively slender metatarsals; therefore, we cannot comment on the potentially different habitat preferences of Longirostromeryx and Parablastomeryx.

\section{Morphospace Occupation Changes Through Time}

Over the entire duration of the Neogene, it is clear that the faunas that have the highest ecologic and taxonomic diversity are those that lived during the Middle Miocene Climatic Optimum (MMCO) and prior to the formation of the East Antarctic ice sheet, which led to a concomitant drop in global temperature (Figure 6). In particular, the Early Clarendonian 6-Burge Quarry assemblage - the classical "Clarendonian Chronofauna" of Webb - constitutes the most diverse artiodactyl fauna included in the analysis (14 genera); interestingly, this assemblage dates to the start of the Neogene cooling and drying trend. Herbivorous artiodactyls displayed their highest diversity in North America during the MMCO (Janis et al., 2000, 2004). Additionally, the ecosystems of the first half of the Miocene produced abundant resources for browsers, which dominated artiodactyl communities prior to the middle Miocene (Janis et al., 2004). These highly rich, predominantly browsing (note that some browsing ungulates were excluded from this study, including artiodactyls such as tayassuids, and perissodactyls such as tapirs and anchitheriine horses) mammal communities from the late early to middle Miocene indicate a higher level of primary productivity than seen today, which might have been a consequence of elevated levels of atmospheric $\mathrm{CO}_{2}$ (Janis et al., 2004; Kürschner et al., 2015). Phytolith evidence indicates that the prevailing ecosystems during this time were most likely savannah woodlands dominated by pooid grasses: plant macrofossils and palynofloras also suggest that grassdominated habitats might have started to expand during this time (Strömberg, 2011). Faunas 3-Thomson Quarry, 5-Norden Bridge Quarry and 6-Burge Quarry, which occurred during or immediately after the MMCO, are the most diverse faunas of the North American Neogene (Figure 7) and are also the ones that most closely resemble the modern Serengeti artiodactyl fauna (Table 6).

Starting in the late Miocene, ungulate faunas became significantly less diverse, with both browsers and mixed feeders decreasing in numbers (Figure 6: only cameline camelids, some dromomerycids from the tribe Cranioceratini, some 
antilocaprine pronghorns, and the gelocid Pseudoceras remained; see Appendix 11); in fact, browsers disappeared altogether by the latest Miocene. These less diverse and less disparate faunas (faunas 7 through 11, with the exception of fauna 8-Cambridge Local Fauna) are all statistically different from the fauna of the modern-day Serengeti. Cambridge Local Fauna (fauna No. 8) is the only fauna of the late Miocene to still be very disparate (although not very diverse), due to the presence of the gelocid Pseudoceras. The decrease in diversity seen toward the end of the Neogene has generally been attributed to the increasingly drier and cooler conditions of the period, and the resulting change from woodland savannas, with abundant resources for browsers, to open grasslands, which offer more support to grazers (Janis et al., 2004). Phytoliths, plant macrofossils and palynofloras all indicate the spread of grass-dominated habitats in North America by the latest Miocene and Pliocene (Strömberg, 2011). Janis et al. (2004) highlight that toward the end of the Miocene, there was a decline in total species richness in the Great Plains: that is, a decrease in diversity occurred not only among browsers, but also among grazers and mixed feeders. The present analysis does not include any taxa previously considered as grazers, since this dietary category was largely occupied by equids in the North American Neogene and is thus beyond the scope of this study.

Throughout the Neogene of North America, the morphospace areas occupied by camelids and ruminants never overlapped (Figure 6). In fact, the only fossil taxa that occupied a similar morphospace area to camelids were the protoceratids, which are usually considered as camelid-related tylopods (Prothero, 1998). During the Miocene and Pliocene, camelids and ruminants belonged to equivalent dietary categories and coexisted within the same communities (Janis et al., 2004; Kita et al., 2014). Even so, they occupied divergent morphospaces on the basis of their phylogenetic and morphological differences, as previously mentioned. In the modern world, camelids rarely compete with ruminants. In South America, the dietary preference of camelids (i.e., opportunistic mixed feeding) only overlaps with that of domestic livestock (note that there are no native bovids in South America) and, given the ability of camelids to subsist on a lower food intake than ruminants (Franklin, 2011; Dittmann et al., $2014 a, b)$, the two groups of animals can live alongside each other without competing for resources (Borgnia et al., 2008; Chammem et al., 2010). The fact that Neogene camelids and ruminants plot in different morphospace areas might indicate differential use of resources within the community, and might parallel the situation seen in modern-day faunas (note that no bovids or large mixed feeding ruminants, like the common eland, were present in the Neogene of North America); however, we cannot ignore the possible contribution of phylogeny to their separation in morphospace. The flexible discriminant analysis, which takes phylogenetic information into account, supports the notion that camelids and ruminants belonged to similar dietary categories.

Janis et al. (1994) note that, during the Miocene, the relative body sizes of equids and ruminants varied depending on their dietary preferences: browsing horses were larger (or smaller) than browsing ruminants, and mixed feeding and grazing artiodactyls were larger (camelids) or smaller (ruminants) than mixed feeding and grazing equids. These differences were attributed to their different digestive physiologies. Throughout the Neogene, the artiodactyls in our study were mostly browsers or mixed feeders, and camelids always displayed larger body sizes than ruminants, perhaps because of their different digestive physiologies and metabolic rates (camelids have lower metabolic rates than true ruminants, an attribute that makes them more efficient in arid conditions [Dittmann et al., 2014a]).

In a separate correspondence analysis (Appendix 13) the extant camelines and extinct camelids fall in comparable morphospace areas along all three axes, but the lamines do not plot in the same area of the morphospace. Some extinct camelids share similar scores on axis two (but not on axis one) with the extant lamines, including Stenomylus, Camelops and Hemiauchenia. The Bactrian camel (Camelus bactrianus) and the dromedary (Camelus dromedarius) plot near to the common eland, along with several extinct camelids. The guanaco (Lama guanicoe) and the llama (Lama glama) plot between the morphospaces of medium-sized browsing and grazing ungulates, and the vicuña (Vicugna vicugna) and the alpaca (Vicugna pacos) plot relatively close to the medium-sized grazing ungulates; some of the extinct antilocaprids also plot near to the lamines. It is notable that, even though camelids and ruminants can occupy similar areas of morphospace, this did not happen in the North American Neogene. Note, however, that there were no large ruminants in North America, but the eland of Africa (and to a lesser extent the African buffalo) does cluster with some extinct camelids. The discrepancies in morphospace occupancy between camelids and ruminants could be related to differences in morphology and physiology; camelids display a long-term pattern of adaptation to arid habitats with sparse food resources, in part due to their lower metabolic rates (Franklin, 2011; Dittmann et al., 2014a). Likewise, a comparative genomic analysis of extant camelids, including the Bactrian camel, the dromedary and the alpaca, revealed a number of physiological mechanisms related to the desert adaptations within the genus Camelus and those of their ancestors (Wu et al., 2014).

However, the lack of North American ruminants in the camelid area of the morphospace could also be a matter of incumbency. Schenk et al. (2013) suggest that the first colonizers of a particular region diversify faster than subsequent colonizers with similar niches. Camelids appeared in North America during the middle Eocene, approximately 45.9 million years ago (Honey et al., 1998), whereas the two earliest ruminant families, the small-sized Hypertragulidae and Leptomerycidae, are relatively younger and appear in North America approximately 41.3 million years ago (Webb, 1998b). This might have allowed camelids to diversify within particular niches that would have then become unavailable for later colonizers, such as the dromomerycids and antilocaprids, which did not appear in North America until the early Miocene (Janis and Manning, 1998a,b). The extraordinary diversification of equids from the Eocene onward, and their shift to predominantly grazing behavior toward the end of the Miocene (Wang et al., 1994; Semprebon et al., 2016), might have contributed to largely excluding camelids from the grazing niche. This stems from the fact that the digestive physiology of hindgut fermenters, such as equids, allows them to better tolerate lower quality herbage, which proved advantageous 
as forage quality decreased toward the end of the Miocene with increasing aridity and seasonality (Janis et al., 1994).

However, we consider that the occupancy of "camelid morphospace" may carry a real environmental signal. North America was evidently more arid than the Old World during the Neogene (Eronen et al., 2012): note that the common eland (the only bovid to cluster with the extinct camelids) is among the most arid-adapted of the African bovids, and is similar in body size and diet (mixed feeding) to these North American camelids. The morphophysiological adaptations of extant camelids must date back to at least the split between lamines and camelines, which would be around the early Miocene based on both anatomical (Honey et al., 1998) and molecular (Heintzman et al., 2015) data. While the Bactrian camel and the dromedary (tribe Camelini) have better physiological adaptations to harsh desert environments than alpacas (tribe Lamini), both tribes had an estimated increase in population size during transitions to colder and more arid conditions, such as the middle Pleistocene transition (Wu et al., 2014). Perhaps camelids were already adapted to arid conditions by the early Miocene, whereas the immigrant ruminants would not have been so fortunate.

\section{CONCLUSION}

We present the first quantitative characterization of the ecomorphology of the artiodactyl faunas from the Neogene North American savannas and how they compare with their counterparts from the present-day African savannas, such as the Serengeti. Our study suggests that, in broad terms, the extinct ruminants are readily comparable to small to medium-sized browsing and mixed feeding bovids. North American camelids are occasionally similar to medium-sized to large grazing and browsing bovids, but for the most part fall outside the ruminant morphospace. Nonetheless, a significant number of camelid taxa plot close to the common eland (an arid habitat mixed feeder; camelids are also largely classified as mixed feeders in our analysis), possibly indicative of habitat differences between the Serengeti and the Neogene savannas of North America. Isotopic data show that there was a shift toward greater aridity in North America during the Miocene (see Mix et al., 2013; Chamberlain et al., 2014), and paleofaunal data indicate that the shift happened in advance of the late Neogene aridification of the Old World (Eronen et al., 2012). This study serves to highlight the important role that faunal composition (especially large herbivorous mammals) can play in understanding past climatic and environmental conditions.

Analysis of changes in morphospace occupation by artiodactyls throughout the Neogene reveals that the morphospaces occupied by camelids and ruminants never overlapped in any faunal assemblage at any point in time. We propose that this is not simply a phylogenetic effect, but potentially indicative of camelids and ruminants occupying different ecological niches, perhaps owing in part to physiological differences. We corroborate the conclusions of Janis et al. (2004), namely that the richest and most diverse faunas occurred during the warmest and most humid times, and declined with the cooling and drying trend that affected northern latitudes from the second half of the Miocene onward. Additionally, a transition from browser-rich communities to habitats mainly (or solely) inhabited by mixed feeders was also evident. Therefore, not all the Neogene savannas of North America were comparable to those of modern-day Africa, and those that were comparable in diversity were different in ecomorphological disparity. In terms of diversity and ecomorphological disparity, only those faunas that existed during or immediately after the Middle Miocene Climatic Optimum (MMCO), are statistically comparable to those of the Serengeti (keeping in mind that the area of morphospace occupied by North American Neogene camelids is mostly unoccupied in modern-day savannas). With the decline in temperatures and levels of precipitation in the later Miocene, and the concomitant shift to grass-dominated habitats, these faunas were no longer statistically comparable in diversity and disparity to those from modern-day African savannas.

In conclusion, many of the results obtained in these analyses are consistent with what was previously known regarding the faunal evolution of artiodactyls during the Neogene. However, our results only partly support the view of Webb (1977, p. 364) that North American Miocene savanna faunas were "fully comparable to present-day African savannas." While many ruminant taxa might have had comparable ecomorphological traits to those of some present-day bovids, camelids were largely occupying a morphospace different from that of bovids, perhaps indicative of more arid environmental conditions than those characteristic of modern African savannas (as proposed by Eronen et al., 2012). This study has quantified changes in morphospace occupation of artiodactyl faunas spanning the early Miocene to the earliest Pleistocene, and can be used as a starting point for more in-depth analyses of the causes behind the community dynamics of North American artiodactyls during the Neogene. Avenues for further research include quantitatively analyzing the diversity and ecomorphological disparity of the autochthonous Neogene South American ungulate faunas in the context of the changing environmental conditions of the Neogene.

\section{DATA AVAILABILITY STATEMENT}

All the datasets used in this study are in the article/Supplementary Material.

\section{ETHICS STATEMENT}

Ethical review and approval was not required for the animal study because all the data used in this study was obtained from photographs of fossils and, in the case of extant taxa, from online databases. No live subjects were used in this study.

\section{AUTHOR CONTRIBUTIONS}

NM-G compiled and analyzed the data, wrote the manuscript and made the figures and tables. LS and CJ supervised NM-G during her Palaeobiology MSc at the University of 
Bristol. LS provided the protocols for data analysis and contributed to the writing and editing of the manuscript. CJ coordinated the project, collected photographs of the fossil specimens and hypsodonty data, and contributed to the writing and editing of the manuscript.

\section{FUNDING}

NM-G was funded by a postgraduate scholarship (\#689870) from CONACYT (Consejo Nacional de Ciencia y Tecnologia; National Council of Science and Technology), Mexico. LS was funded by an Academy of Finland Postodoctoral grant (275551). The publication fees of this manuscript were waived by Frontiers in recognition of NM-G's best student poster award during the 64th Symposium for Vertebrate Palaeontology and Comparative Anatomy (SVPCA) in Liverpool, August 2016. NM-G would like to thank Peter Falkingham and all the other organizers of SVPCA 2016 for this award and Frontiers for covering the fees associated with this paper.

\section{REFERENCES}

Bache, B. W., and Chesworth, W. (2016). "Biomes and their soils," in Encyclopedia of Soil Science, ed. W. Chesworth (Dordrecht: Springer), 62-70.

Bapst, D. W. (2012). Paleotree: an R package for paleontological and phylogenetic analyses of evolution. Methods Ecol. Evol. 3, 803-807. doi: 10.1111/j.2041-210X. 2012.00223.x

Barr, W. A. (2018). "Ecomorphology," in Methods in Paleoecology: Reconstructing Cenozoic Terrestrial Environments, eds D. A. Croft, D. F. Su, and S. W. Simpson (Cham: Springer), 339-349.

Baskin, J., and Thomas, R. (2015). A review of Camelops (Mammalia, Artiodactyla, Camelidae), a giant llama from the Middle and Late Pleistocene (Irvingtonian and Rancholabrean) of North America. Hist. Biol. 28, 120-127. doi: 10.1080/ 08912963.2015.1020800

Borgnia, M., Vilá, B. L., and Cassini, M. H. (2008). Interaction between wild camelids and livestock in an Andean semi-desert. J. Arid Environ. 72, 21502158. doi: $10.1016 /$ j.jaridenv.2008.07.012

Brussatte, S. L., Benton, M. J., Ruta, M., and Lloyd, G. T. (2008). Superiority, competition, and opportunism in the evolutionary radiation of dinosaurs. Science 321, 1485-1488. doi: 10.1126/science.1161833

Cerling, T. E. (1992). Development of grasslands and savannas in East Africa during the Neogene. Palaeogeogr. Palaeoclimatol. Palaeoecol. 97, 241-247. doi: 10.1016/0031-0182(92)90211-m

Chamberlain, C. P., Winnick, M. J., Mix, H. T., Chamberlain, S. D., and Maher, K. (2014). The impact of Neogene grassland expansion and aridification on the isotopic composition of continental precipitation. Glob. Biogeochem. Cycles 28, 992-1004. doi: 10.1002/2014GB004822

Chammem, M., Khorchani, T., Selmi, S., and Nouira, S. (2010). Coexistence between camels and wild animals. J. Camel Sci. 3, 6-18. doi: 10.1073/pnas. 1519508113

Chen, K. Y. C. (2015). Ecology and Morphology of the Late Miocene Musk Deer, Longirostromeryx wellsi (Artiodactyla: Moschidae: Blastomerycinae). Master's thesis, University of Nebraska, Lincoln, NE.

Clauss, M, Hofmann, R. R, Streich, W. J, Fickel, J., and Hummel, J. (2008). Higher masseter muscle mass in grazing than in browsing ruminants. Oecologia 157, 377-385. doi: 10.1007/s00442-008-1093-z

Croft, D. A., Engelman, R. K., Dolgushina, T., and Wesley, G. (2017). Diversity and disparity of sparassodonts (Metatheria) reveal non-analogue nature of ancient South American mammalian carnivore guilds. Proc. R. Soc. B 285:20172012. doi: $10.1098 /$ rspb.2017.2012

\section{ACKNOWLEDGMENTS}

NM-G would like to thank Suresh Singh for his help running the statistical analyses and convex hull area calculations, Dr. Juha Saarinen for providing ungulate body mass data, Lars Werdelin for advice about the use of correspondence analysis, and Steve Zhang for providing valuable bibliographical material. CJ acknowledges the late S. David Webb for many conversations over many decades about the North American savanna faunas. All authors would like to thank the editor of this manuscript, Prof. CS, as well as Dr. TG and Prof. SB for their valuable comments that helped strengthen this study.

\section{SUPPLEMENTARY MATERIAL}

The Supplementary Material for this article can be found online at: https://www.frontiersin.org/articles/10.3389/feart. 2020.00191/full\#supplementary-material

D’Ammando, G., Parrini, F., Attorre, F., and Boitani, L. (2014). Observations on dry season grazing by eland in Magaliesberg Nature Reserve, South Africa. Afr. J. Ecol. 53, 112-115. doi: 10.1111/aje.12164

Damuth, J. (1982). "Taxon-free characterization of animal communities," in Terrestrial Ecosystems Through Time, eds A. K. Behrensmeyer, J. D. Damuth, W. A. DiMichele, R. Potts, H. Sues and S. L. Wing (Chicago, IL: University of Chicago Press), 183-203.

Damuth, J., and Janis, C. M. (2011). On the relationship between hypsodonty and feeding ecology in ungulate mammals, and its utility in palaeoecology. Biol. Rev. 86, 733-758. doi: 10.1111/j.1469-185X.2011.00176.x

Davis, E. B. (2007). "Family Antilocapridae," in The Evolution of Artiodactyls, eds D. R. Prothero, and S. E. Foss (Baltimore, MD: The Johns Hopkins University Press), 227-240.

Dittmann, M. T., Hummel, J., Runge, U., Galeffi, C., Kreuzer, M., and Clauss, M. (2014a). Characterising an artiodactyl family inhabiting arid habitats by its metabolism: low metabolism and maintenance requirements in camelids. J. Arid Environ. 107, 41-48. doi: 10.1016/j.jaridenv.2014.04.005

Dittmann, M. T., Runge, U., Lang, R. A., Moser, D., Galeffi, C., Kreuzer, M., et al. (2014b). Methane emission by camelids. PLoS One 9:e94363. doi: 10.1371/ journal.pone.0094363

Dompierre, H., and Churcher, C. S. (1996). Premaxillary shape as an indicator of the diet of seven extinct late Cenozoic New World camels. J. Vertebr. Paleontol. 16, 141-148. doi: 10.1080/02724634.1996.10011292

Du Toit, J. T., and Cumming, D. H. M. (1999). Functional significance of ungulate diversity in African savannas and the ecological implications of the spread of pastoralism. Biodivers. Conserv. 8, 1643-1661. doi: 10.1023/A:100895972 1342

Eronen, J. T., Ataabadi, M. M., Micheels, A., Karme, A., Bernor, R. L., and Fortelius, M. (2009). Distribution history and climatic controls of the Late Miocene Pikermian chronofauna. Proc. Natl. Acad. Sci. U.S.A. 106, 11867-11871. doi: 10.1073/pnas.0902598106

Eronen, J. T., Fortelius, M., Micheels, A., Portmann, F. T., Poulamäki, K., and Janis, C. M. (2012). Neogene aridification of the Northern Hemisphere. Geology 40, 823-826 doi: 10.1130/g33147.1

Estes, R. D. (2012). The Behavior Guide to African Mammals: Including Hoofed Mammals, Carnivores, Primates. (Berkeley, CA: University of California Press.)

Flowers, B. P., and Kennett, J. P. (1993). Middle Miocene ocean-climate transition: high resolution oxygen and carbon isotopic records from Deep Sea Drilling Project Site 588A, southwest Pacific. Paleoceanography 8, 811-843. doi: 10.1029/ 93PA02196 
Fortelius, M. (2016). Data from: New and Old Worlds Database of Fossil Mammals (NOW). Available online at: http://www.helsinki.fi/science/now/ (accessed on June 2016).

Fortelius, M., Bibi, F., Tang, H., Žliobaitë,? I., Eronen, J. T., and Kaya, F. (2019). The nature of the Old World savannah palaeobiome. Nat. Ecol. Evol.3:504. doi: 10.1038/s41559-019-0857-7

Fortelius, M., Eronen, J., Jernvall, J., Liu, L., Pushkina, D., Rinne, J., et al. (2002). Fossil mammals resolve regional patters of Eurasian climate change over 20 million years. Evol. Ecol. Res. 4, 1005-1016.

Fortelius, M., and Solounias, N. (2000). Functional characterization of ungulate molars using the abrasion-attrition wear gradient: a new method for reconstructing paleodiets. Am. Mus. Novit. 3301, 1-36. doi: 10.1206/00030082(2000)301<0001:fcoumu $>2.0$. co; 2

Fox, D. L., and Koch, P. L. (2004). Carbon and oxygen isotopic variability in Neogene paleosol carbonates: constraints on the evolution of the C4-grasslands of the Great Plains, USA. Palaeogeogr. Palaeoclimatol. Palaeoecol. 207, 305-329. doi: 10.1016/j.palaeo.2003.09.030

Fox, D. L., Pau, S., Taylor, L., Strömberg, C. A. E., Osborne, C. P., Bradshaw, C., et al. (2018). Climatic controls on C4 grassland distributions during the Neogene: a model-data comparison. Front. Ecol. Evol. 6:147. doi: 10.3398/fevo.2018.00147

Franklin, W. L. (2011). "Family Camelidae (Camels)," in Handbook of the Mammals of the World: Hoofed Mammals, Vol. 2, eds D. E. Wilson, and R. A. Mittermeier (Barcelona: Lynx Edicions), 206-247.

Fraser, D., Haupt, R. J., and Barr, W. A. (2018). Phylogenetic signal in tooth wear dietary niche proxies. Ecol. Evol. 8, 5355-5368. doi: 10.1002/ece3.4052

Fraser, D., and Theodor, J. M. (2011). Comparing ungulate dietary proxies using discriminant function analysis. J. Morphol. 272, 1513-1526. doi: 10.1002/jmor. 11001

Fraser, D., and Theodor, J. M. (2013). Ungulate diets reveal patterns of grassland evolution in North America. Palaeogeogr. Palaeoclimatol. Palaeoecol. 369, 409421. doi: 10.1016/j.palaeo.2012.11.006

Frick, C. (1937). Horned ruminants of North America. Bull. Am. Mus. Nat. Hist. 69, 1-669.

Geisler, J. H., and Uhen, M. D. (2005). Phylogenetic relationships of extinct cetartiodactyls: results of simultaneous analyses of molecular, morphological, and stratigraphic data. J. Mamm. Evol. 12, 145-160. doi: 10.1007/s10914-0054963-8

Greaves, W. S. (1991). A relationship between premolar loss and jaw elongation in selenodont artiodactyls. Zool. J. Linn. Soc. Lond. 101, 121-129. doi: 10.1111/j. 1096-3642.1991.tb00889.x

Greenacre, M. J., and Vrba, E. S. (1984). Graphical display and interpretation of antelope census data in African wildlife using correspondence analysis. Ecology 65, 984-997. doi: 10.2307/1938070

Groves, C. P., and Leslie, D. M. Jr. (2011). "Family Bovidae (hollow-horned ruminants)," in Handbook of the Mammals of the World: Hoofed Mammals, Vol. 2, eds D. E. Wilson, and R. A. Mittermeier (Barcelona: Lynx Edicions), 444-779.

Hammer, Ø., Harper, D. A. T., and Ryan, P. D. (2001). PAST: paleontological statistics software package for education and data analysis. Palaeontol. Electron. 4:9.

Harrison, J. A. (1979). Revision of the Camelinae (Artiodactyla, Tylopoda) and description of the new genus Alforjas. Univ. Kansas Paleontol. Contrib. 95, $1-20$.

Hastie, T., Tibshirani, R., and Buja, A. (1994). Flexible discriminant analysis by optimal scoring. J. Am. Stat. Assoc. 89, 1255-1270. doi: 10.2307/2290989

Heintzman, P. D., Zazula, G. D., Cahill, J. A., Reyes, A. V., MacPhee, R. D. E., and Shapiro, B. (2015). Genomic data from extinct North American Camelops revise camel evolutionary history. Mol. Biol. Evol. 32, 2433-2400. doi: 10.1093/ molbev/msv128

Hibbard, C. W. (1951). An antilocaprid from the Lower Pliocene of Beaver County, Oklahoma. Trans. Kansas Acad. Sci. 54, 387-390. doi: 10.2307/3625719

Hoffman, R. R., and Stewart, D. R. M. (1972). Grazer or browser: a classification based on the stomach-structure and feeding habit of East African ruminants. Mammalia 36, 226-240. doi: 10.1515/mamm.1972.36.2.226

Honey, J. G., Harrison, J. A., Prothero, D. R., and Stevens, M. S. (1998). "Camelidae" in Evolution of Tertiary Mammals of North America.: Terrestrial Carnivores, Ungulates, and Ungulate-like Mammals, Vol. 1, eds C. M. Janis, K. M. Scott, and L. L. Jacobs (New York, NY: Cambridge University Press), $439-462$.
Jacobs, B. F., Kingston, J. D., and Jacobs, L. L. (1999). The origin of grass-dominated ecosystems. Ann. Mo. Bot. Gard. 86, 590-643. doi: 10.2307/2666186

Janis, C. M. (1982). Evolution of horns in ungulates: ecology and paleoecology. Biol. Rev. 57, 261-318. doi: 10.1111/j.1469-185x.1982.tb00370.x

Janis, C. M. (1988). “An estimation of tooth volume and hypsodonty indices in ungulate mammals, and the correlation of these factors with dietary preferences," in Proceedings of the 7th International Symposium on Dental Morphology, Paris, 1986, eds D. E. Russell, J. P. Santoro, and D. SigogneauRussell (Paris: Mémoirs de Musée d'Histoire Naturelle), 367-387.

Janis, C. M. (1990). Correlation of cranial and dental variables with body size in ungulates and macropodoids. Mem. Qld. Mus. 28, 349-366.

Janis, C. M. (1995). "Correlations between craniodental morphology and feeding behavior in ungulates: reciprocal illumination between living and fossil taxa," in Functional Morphology in Vertebrate Paleontology, ed. J. J. Thomason (New York, NY: Cambridge University Press), 76-98.

Janis, C. M., Damuth, J., and Theodor, J. M. (2000). Miocene ungulates and terrestrial primary productivity: where have all the browsers gone? Proc. Natl. Acad. Sci. U.S.A. 97, 7899-7904. doi: 10.1073/pnas.97.14.7899

Janis, C. M., Damuth, J., and Theodor, J. M. (2002a). The origins and evolution of the North American grassland biome: the story from the hoofed mammals. Palaeogeogr. Palaeoclimatol. Palaeoecol. 177, 183-198. doi: 10.1016/S00310182(01)00359-5

Janis, C. M., Damuth, J., and Theodor, J. M. (2004). The species richness of Miocene browsers, and implications for habitat type and primary productivity in the North American grassland biome. Palaeogeogr. Palaeoclimatol. Palaeoecol. 207, 371-398. doi: 10.1016/j.palaeo.2003.09.032

Janis, C. M., and Ehrhardt, D. (1988). Correlation of relative muzzle width and relative incisor width with dietary preference in ungulates. Zool. J. Linn. Soc. Lond. 92, 267-284. doi: 10.1111/j.1096-3642.1988.tb01513.x

Janis, C. M., and Fortelius, M. (1988). On the means whereby mammals achieve increased functional durability of their dentitions, with special reference to limiting factors. Biol. Rev. 63, 197-230. doi: 10.1111/j.1469-185X.1988.tb00 630.x

Janis, C. M., Gordon, I. J., and Illius, A. W. (1994). Modelling equid/ruminant competition in the fossil record. Hist. Biol. 8, 15-29. doi: 10.1080/ 10292389409380469

Janis, C. M., and Manning, E. (1998a). “Antilocapridae," in Evolution of Tertiary Mammals of North America: Terrestrial Carnivores, Ungulates, and Ungulatelike Mammals, Vol. 1, eds C. M. Janis, K. M. Scott and L. L. Jacobs (New York, NY: Cambridge University Press), 491-507. doi: 10.1017/cbo9780511529924. 035

Janis, C. M., and Manning, E. (1998b). “Dromomerycidae," in Evolution of Tertiary Mammals of North America: Terrestrial Carnivores, Ungulates, and Ungulatelike Mammals, Vol. 1, eds C. M. Janis, K. M. Scott, and L. L. Jacobs (New York, NY: Cambridge University Press), 477-490. doi: 10.1017/cbo9780511529924. 034

Janis, C. M., Shoshitaishvili, B., Kambic, R., and Figueirido, B. (2012). On their knees: distal femur asymmetry in ungulates and its relationship to body size and locomotion. J. Vertebr. Paleontol. 32, 433-445. doi: 10.1080/02724634.2012. 635737

Janis, C. M., Theodor, J. M., and Boisvert, B. (2002b). Locomotor evolution in camels revisited: a quantitative analysis of pedal anatomy and the acquisition of the pacing gait. J. Vertebr. Paleontol. 22, 110-121. doi: 10.1671/02724634(2002)022 \%5B0110:leicra $\ \% 5$ D2.0.co;2

Jimenez-Hidalgo, E., and Carranza-Castañeda, O. (2010). Blancan camelids from San Miguel de Allende, Guanajuato, central México. J. Paleontol. 84, 51-65. doi: 10.1666/08-154.1

Kappelman, J. (1988). Morphology and locomotor adaptations of bovid femur in relation to habitat. J. Morphol. 198, 119-130. doi: 10.1002/jmor.1051980111

Kappelman, J., Plummer, T., Bishop, L., Duncan, A., and Appleton, S. (1997). Bovids as indicators of Plio-Pleistocene paleoenvironments in east Africa. J. Hum. Evol. 32, 229-256. doi: 10.1006/jhev.1996.0105

Kaya, F., Bibi, F., Žliobaitë, I., Eronen, J. T., Hui, T., and Fortelius, M. (2018). The rise and fall of the Old World savannah fauna and the origins of the African savannah biome. Nat. Ecol. Evol. 2, 241-246. doi: 10.1038/s41559-0170414-1

Kelly, T. S. (1992). New Middle Miocene camels from the Caliente Formation, Cuyama Valley Badlands, California. Paleobios 13, 1-22. 
Kita, Z. A., Secord, R., and Boardman, G. S. (2014). A new stable isotope record of Neogene paleoenvironments and mammalian paleoecologies in the western Great Plains during the expansion of C4 grasslands. Palaeogeogr. Palaeoclimatol. Palaeoecol. 399, 160-172. doi: 10.1016/j.palaeo.2014.02.013

Kovarovic, K., Su, D. F., and Lintulaakso, K. 2018. "Mammal community structure analysis," in Methods in Paleoecology: Reconstructing Cenozoic Terrestrial Environments, eds D. A. Croft, D. F. Su, and S. W. Simpson (Cham: Springer), 351-372. doi: 10.1007/978-3-319-94265-0_16

Kürschner, W. M., Kvacek, Z., and Dilcher, D. L. (2015). The impact of Miocene atmospheric carbon dioxide fluctuations on climate and the evolution of terrestrial ecosystems. Proc. Natl. Acad. Sci. U.S.A. 105, 449-453. doi: 10.1073/ pnas.0708588105

Lehmann, S. B., Braun, D. R., Dennis, K. J., Patterson, D. B., Stynder, D. D., Bishop, L. C., et al. (2016). Stable isotopic composition of fossil mammal teeth and environmental change in southwestern South Africa during the Pliocene and Pleistocene. Palaeogeogr. Palaeoclimatol. Palaeoecol. 457, 396-408. doi: 10.1016/ j.palaeo.2016.04.042

Luoys, J., Montanari, S., Plummer, T., Hertel, F., and Bishop, L. (2013). Evolutionary divergence and convergence in shape and size within African antelope proximal phalanges. J. Mamm. Evol. 20, 239-248. doi: 10.1007/s10914012-9211-4

MacFadden, B. (1998). "Equidae," in Evolution of Tertiary Mammals of North America: Terrestrial Carnivores, Ungulates, and Ungulate-Like Mammals, Vol. 1, eds C. M. Janis, K. M. Scott, and L. L. Jacobs (New York, NY: Cambridge University Press), 537-559.

Matthew, W. D. (1908). Osteology of Blastomeryx and phylogeny of the American Cervidae. Bull. Am. Mus. Nat. Hist. 24, 535-562.

Mendoza, M., Janis, C. M., and Palmqvist, P. (2002). Characterizing complex craniodental patterns related to feeding behaviour in ungulates: a multivariate approach. J. Zool. 258, 223-246. doi: 10.1017/S0952836902001346

Mendoza, M., and Palmqvist, P. (2008). Hypsodonty in ungulates: an adaptation for grass consumption or for foraging in open habitat. J. Zool. 274, 134-142. doi: 10.1111/j.1469-7998.2007.00365.x

Métais, G., and Vislobokova, I. (2007). "Basal ruminants," in The Evolution of Artiodactyls, eds D. R. Prothero, and S. E. Foss (Baltimore, MD: The Johns Hopkins University Press), 189-212.

Mix, H. T., Winnick, M. J., Mulch, A., and Chamberlain, C. P. (2013). Grassland expansion as an instrument of hydrologic change in Neogene western North America. Earth Planet. Sci. Lett. 37, 73-83. doi: 10.1016/j.epsl.2013.07.032

Morgan, G. S., and White, R. S. Jr. (2005). "Miocene and Pliocene vertebrates from Arizona," in Vertebrate Paleontology in Arizona, eds A. B. Heckert and S. G. Lucas (Albuquerque, NM: New Mexico Museum of Natural History and Science Bulletin), 114-135.

Motani, R., and Schmitz, L. (2011). Phylogenetic versus functional signals in the evolution of form-function relationships in terrestrial vision. Evolution 65, 2245-2257. doi: 10.1111/j.1558-5646.2011.01271.x

Paradis, E., and Schliep, K. (2018). Ape 5.0: an environment for modern phylogenetics and evolutionary analyses in R. Bioinformatics $35,526-528$. doi: 10.1093/bioinformatics/bty633

Patton, T. H., and Taylor, B. E. (1971). The Synthetoceratinae (Mammalia, Tylopoda, Protoceratidae). Bull. Am. Mus. Nat. Hist. 145, 119-218.

Pebesma, E., Bivand, R., Rowlingson, B., Gomez-Rubio, V., Hijimans, R., Sumner, M., et al. (2018). sp: Classes and Methods for Spatial Data. R package version 1.3.1. Available online at: https://cran.r-project.org/web/packages/sp (accessed on August 2019).

Pennell, M. W., Eastman, J. M., Slater, G. J., Brown, J. W., Uyeda, J. C., FitzJohn, R. G., et al. (2014). Geiger v2.0: an expanded suite of methods for fitting macroevolutionary models to phylogenetic trees. Bioinformatics 30, 2216-2218. doi: 10.1093/bioinformatics/btu181

Pérez-Barbería, F. J., and Gordon, I. J. (1999). The functional relationship between feeding type and jaw and cranial morphology in ungulates. Oecologia 118, 157-165. doi: 10.1007/s004420050714

Pérez-Barbería, F. J., and Gordon, I. J. (2001). Relationships between oral morphology and feeding style in the Ungulata: a phylogenetically controlled evaluation. Proc. R. Soc. Lond. B 268, 1023-1032. doi: 10.1098/rspb.2001. 1619

Peters, R. H. (1983). The Ecological Implications of Body Size. Cambridge: Cambridge University Press.
Pierce, E. L., van de Flierdt, T., Williams, T., Hemming, S. R., Cook, C. P., and Passchier, S. (2017). Evidence for a dynamic East Antarctic ice sheet during the mid-Miocene climate transition. Earth Planet. Sc. Lett. 478, 1-13. doi: 10.1016/ j.epsl.2017.08.011

Plummer, T. W., Ferraro, J. V., Louys, J., Hertel, F., Alemseged, Z., Bobe, R., et al. (2015). Bovid ecomorphology and hominin paleoenvironments of the Shungura Formation, lower Omo River valley, Ethiopia. J. Hum. Evol. 88, 108-126. doi: 10.1016/j.jhevol.2015.06.006

Price, S. A., Bininda-Emons, O. R. P., and Gittleman, J. L. (2005). A complete phylogeny of the whales, dolphins and even-toed hoofed mammals (Cetartiodactyla). Biol. Rev. 80, 445-473. doi: 10.1017/S146479310500 6743

Prothero, D. R. (1998). "Protoceratidae," in Evolution of Tertiary Mammals of North America.: Terrestrial Carnivores, Ungulates, and Ungulate-like Mammals, Vol., eds C. M. Janis, K. M. Scott, and L. L. Jacobs (New York, NY: Cambridge University Press), 431-438. doi: 10.1017/cbo9780511529924.031

Prothero, D. R. (2008). "Systematics of the musk deer (Artiodactyla: Moschidae: Blastomerycinae) from the Miocene of North America," in Neogene Mammals, eds S. G. Lucas, G. S. Morgan, J. A. Spielmann, and D. R. Prothero (Albuquerque, NM: New Mexico Museum of Natural History and Science Bulletin), 207-224.

Prothero, D. R., and Liter, M. R. (2008). "Systematics of the dromomerycines and aletomerycines (Artiodactyla: Palaeomerycidae) from the Miocene and Pliocene of North America," in Neogene Mammals, eds S. G. Lucas, G. S. Morgan, J. A. Spielmann, and D. R. Prothero (Albuquerque, NM: New Mexico Museum of Natural History and Science Bulletin), 273-298.

Prothero, D. R., Liter, M. R., Barnes, L. G., Wang, X., Mitchell, E., McLeod, S., et al. (2008). "Land mammals from the Middle Miocene Sharktooth Hill Bonebed, Kern County, California," in Neogene Mammals, eds S. G. Lucas, G. S. Morgan, J. A. Spielmann, and D. R. Prothero (Albuquerque, NM: New Mexico Museum of Natural History and Science Bulletin), 299-314.

Prothero, D. R., and Ludtke, J. A. (2007). "Family protoceratidae," in The Evolution of Artiodactyls, eds D. R. Prothero, and S. E. Foss (Baltimore, MD: The Johns Hopkins University Press), 169-176.

Retallack, G. J. (1997). Neogene expansion of the North American Prairie. Palaios 12, 380-390. doi: 10.2307/3515337

RStudio Team (2015). RStudio: Integrated Development for R. Boston, MA: RStudio, Inc.

Rubenstein, D. I. (2011). "Family Equidae (horses and relatives)," in Handbook of the Mammals of the World.: Hoofed Mammals, Vol. 2, eds D. E. Wilson and R. A. Mittermeier (Barcelona: Lynx Edicions), 106-143.

Saarinen, J. J., Boyer, A. G., Brown, J. H., Costa, D. P., Morgan Ernest, S. K., Evans, A. R., et al. (2014). Patterns of maximum body size evolution in Cenozoic land mammals: eco-evolutionary processes and abiotic forcing. Proc. R. Soc. Lond. B 281:20132049. doi: 10.1098/rspb.2013.2049

Sarkar, D. (2008). Lattice: Multivariate data visualization with R. New York, NY: Springer.

Schenk, J. J., Rowe, K. C., and Steppan, S. J. (2013). Ecological opportunity and incumbency in the diversification of repeated continental colonizations by muroid rodents. Syst. Biol. 62, 837-864. doi: 10.1093/sysbio/syt050

Scherer, C. S. (2013). The Camelidae (Mammalia, Artiodactyla) from the Quaternary of South America: cladistic and biogeographic hypotheses. J. Mamm. Evol. 20, 45-56. doi: 10.1007/s10914-012-9203-4

Schneider, C. A., Rasband, W. S., and Eliceiri, K. W. (2012). NIH Image to ImageJ: 25 years of image analysis. Nat. Methods 9, 671-675. doi: 10.1038/nmeth.2089

Scott, K. M. (1985). Allometric trends and locomotor adaptations in the Bovidae. Bull. Am. Mus. Nat. Hist. 179, 197-288.

Scott, R. S., and Barr, W. A. (2014). Ecomorphology and phylogenetic risk: implications for habitat reconstruction using fossil bovids. J. Hum. Evol. 73, 47-57. doi: 10.1016/j.jhevol.2014.02.023

Semprebon, G., Janis, C., and Solounias, N. (2004). The diets of the Dromomerycidae (Mammalia: Artiodactyla) and their response to Miocene vegetational change. J. Vertebr. Paleontol. 24, 427-444. doi: 10.1671/2431

Semprebon, G., Rivals, F., and Janis, C. M. (2019). The role of grass vs. exogenous abrasives in the paleodietary patterns of North American ungulates. Front. Ecol. Evol. 7:65. doi: 10.3389/fevo.2019.00065

Semprebon, G., Rivals, F., Solounias, N., and Hulbert, R. C. Jr. (2016). Paleodietary reconstruction of fossil horses from the Eocene through Pleistocene of North 
America. Palaeogeogr. Palaeoclimatol. Palaeoecol. 442, 110-127. doi: 10.1016/j. palaeo.2015.11.004

Semprebon, G. M., and Rivals, F. (2007). Was grass more prevalent in the pronghorn past? An assessment of the dietary adaptations of Miocene to Recent Antilocapridae (Mammalia: Artiodactyla). Palaeogeogr. Palaeoclimatol. Palaeoecol. 253, 332-347. doi: 10.1016/j.palaeo.2007.06.006

Semprebon, G. M., and Rivals, F. (2010). Trends in the paleodietary habits of fossil camels from the Tertiary and Quaternary of North America. Palaeogeogr. Palaeoclimatol. Palaeoecol. 295, 131-145. doi: 10.1016/j.palaeo.2010.05.033

Shorrocks, B., and Bates, W. (2015). The Biology of African Savannas. Oxford: Oxford University Press.

Solounias, N., Moelleken, S. M. C., and Plavcan, J. M. (1995). Predicting the diet of extinct bovids using masseteric morphology. J. Vertebr. Paleontol. 15, 795-805. doi: $10.1080 / 02724634.1995 .10011262$

Solounias, N., and Semprebon, G. (2002). Advances in the reconstruction of ungulate ecomorphology with application to early fossil equids. Am. Mus. Novit. 3366, 1-52.

Strömberg, C. A. E. (2002). The origin and spread of grass-dominated ecosystems in the late Tertiary of North America: preliminary results concerning the evolution of hypsodonty. Palaeogeogr. Palaeoclimatol. Palaeoecol. 177, 59-75. doi: 10.1016/S0031-0182(01)00352-2

Strömberg, C. A. E. (2004). Using phytolith assemblages to reconstruct the origin and spread of grass-dominated habitats in the Great Plains of North America during the late Eocene to early Miocene. Palaeogeogr. Palaeoclimatol. Palaeoecol. 207, 239-275. doi: 10.1016/j.palaeo.2003.09.028

Strömberg, C. A. E. (2011). Evolution of grasses and grassland ecosystems. Annu. Rev. Earth Planet. Sci. 39, 517-544. doi: 10.1146/annurev-earth-040809152402

Strömberg, C. A. E., Dunn, R. E., Madden, R. H., Kohn, M. J., and Carlini, A. A. (2013). Decoupling the spread of grasslands from the evolution of grazer-type herbivores in South America. Nat. Commun. 4:1478. doi: 10.1038/ncomms 2508

Taylor, B. E., and Webb, S. D. (1976). Miocene Leptomerycidae (Artiodactyla, Ruminantia) and their relationships. Am. Mus. Novit. 2596, $1-22$.

Tomiya, S. (2013). Body size and extinction risk in terrestrial mammals above the species level. Am. Nat. 182, E196-E214. doi: 10.1086/673489

Varela, L., and Fariña, R. A. (2015). Masseter moment arm as a dietary proxy in herbivorous ungulates. J. Zool. 296, 295-304. doi: 10.1111/jzo.12246

Venables, W. N., and Ripley, B. D. (2002). Modern Applied Statistics with S. New York, NY: Springer.

Wang, Y., Cerling, T. E., and MacFadden, B. J. (1994). Fossil horses and carbon isotopes: new evidence for Cenozoic dietary, habitat, and ecosystem changes in North America. Palaeogeogr. Palaeoclimatol. Palaeoecol. 107, 269-271. doi: 10.1016/0031-0182(94)90099-X

Webb, S. D. (1977). A history of savanna vertebrates in the New World. Part I: North America. Annu. Rev. Ecol. Syst. 8, 355-380. doi: 10.1146/annurev.es.08. 110177.002035

Webb, S. D. (1978). A history of savanna vertebrates in the New World. Part II: South America and the Great Interchange. Annu. Rev. Ecol. Syst. 8, 355-380. doi: 10.1146/annurev.es.09.110178.002141

Webb, S. D. (1983a). A new species of Pediomeryx from the Late Miocene of Florida, and its relationships within the subfamily Cranioceratinae (Ruminantia: Dromomerycidae). J. Mammal. 64, 261-276. doi: 10.2307/ 1380556
Webb, S. D. (1983b). "The rise and fall of the late Miocene ungulate fauna in North America," in Coevolution, ed. M. N. Nitecki (Chicago, IL: University of Chicago Press), 267-306.

Webb, S. D. (1998a). "Cervidae and Bovidae," in Evolution of Tertiary Mammals of North America: Terrestrial Carnivores, Ungulates, and Ungulate-like Mammals, Vol. 1,eds C. M. Janis, K. M. Scott, and L. L. Jacobs (New York, NY: Cambridge University Press), 508-510.

Webb, S. D. (1998b). "Hornless ruminants," in Evolution of Tertiary Mammals of North America: Terrestrial Carnivores, Ungulates, and Ungulate-like Mammals, Vol. 1, eds C. M. Janis, K. M. Scott, and L. L. Jacobs (New York, NY: Cambridge University Press), 463-476.

Webb, S. D. (2008). Revision of the extinct Pseudoceratinae (Artiodactyla: Ruminantia: Gelocidae). Bull. Florida Mus. Nat. Hist. 48, 17-58.

Webb, S. D., Beatty, B. L., and Poinar Jr., G. (2003). New evidence of Miocene Protoceratidae including a new species from Chiapas, Mexico. Bull. Am. Mus. Nat. Hist. 279, 348-367. doi: 10.1206/0003-0090(2003)279<0348:C>2.0.CO;2

Webb, S. D., and Meachen, J. (2004). On the origin of lamine Camelidae including a new genus from the Late Miocene of the High Plains. Bull. Carnegie Mus. Nat. Hist. 36, 349-362.

Webb, S. D., and Taylor, B. E. (1980). The phylogeny of hornless ruminants and a description of the cranium of Archaeomeryx. Bull. Am. Mus. Nat. Hist. 167, 117-158.

Werdelin, L., and Lewis, M. E. (2013). Temporal change in functional richness and evenness in the Eastern African Plio-Pleistocene carnivoran guild. PLoS One 8:e579444. doi: 10.1371/journal.pone.0057944

Wesley-Hunt, G. D., Dehghani, R., and Werdelin, L. (2010). "Comparative ecomorphology and biogeography of Herpestidae and Viverridae (Carnivora) in Africa and Asia," in Carnivoran Evolution: New Views on Phylogeny, Form, and Function, eds A. Goswami and A. Friscia (Cambridge: Cambridge University Press), 246-268.

Wilson, D. E., and Mittermeier, R. A. (2011). Handbook of the Mammals of the World 2: Hoofed Mammals. Barcelona: Lynx Edicions.

Wortman, J. L. (1898). The extinct Camelidae of North America and some associated forms. Bull. Am. Mus. Nat. Hist. 10, 93-143.

Wu, H., Guang, X., Al-Fageeh, M. B., Cao, J., Pan, S., Zhou, H., et al. (2014). Camelid genomes reveal evolution and adaptation to desert environments. Nat. Commun. 5:5188. doi: 10.1038/ncomms6188

Zachos, J., Pagani, M., Sloan, L., Thomas, E., and Billups, K. (2001). Trends, rhythms, and aberrations in global climate 65 Ma to present. Science 292, 686-693. doi: 10.1126/science.1059412

Zurano, J. P., Magalhães, F. M., Asato, A. E., Silva, G., Bidau, C. J., Mesquita, D. O., et al. (2019). Cetartiodactyla: updating a time-calibrated molecular phylogeny. Mol. Phylogenet. Evol. 133, 256-262. doi: 10.1016/j.ympev.2018. 12.015

Conflict of Interest: The authors declare that the research was conducted in the absence of any commercial or financial relationships that could be construed as a potential conflict of interest.

Copyright (c) 2020 Morales-García, Säilä and Janis. This is an open-access article distributed under the terms of the Creative Commons Attribution License (CC BY). The use, distribution or reproduction in other forums is permitted, provided the original author(s) and the copyright owner(s) are credited and that the original publication in this journal is cited, in accordance with accepted academic practice. No use, distribution or reproduction is permitted which does not comply with these terms. 